\title{
The Ultimatum Game: optimal strategies without fairness
}

\author{
by
}

Stephen J. Burnell, Lewis Evans, and Shuntian Yao*

March 1998

School of Economics and Finance

Faculty of Commerce and Administration

Victoria University of Wellington

PO Box 600 Wellington

New Zealand

*The authors acknowledge helpful communication with Vernon Smith, and the very constructive suggestions of an anonymous referee. 


\title{
Ultimatum Game: without fairness
}

\author{
Shuntian Yao
}

School of Economics and Finance

Faculty of Commerce and Administration

Victoria University of Wellington

PO Box 600, Wellington

New Zealand

E-Mail address: Shuntian.Yao@vuw.ac.nz

Fax: 006444955014

\begin{abstract}
The Ultimatum game is simple and this facilitates its use in the study of predictions of game theory. Experimental evidence suggests that it does not predict individual behavior well, unless individuals gain welfare from fairness in transactions, or have expectations about some wider game. Our model excludes any notion of fairness by including (potential) rivalry in transactions. In this game the proposer's expectations yield outcomes that are consistent with experimental evidence. Offers can be large or small, with none in an intermediate range. The consequent
\end{abstract}


distribution appears in Dictator game experiments. Our model explains how it is generated by expectations.

(JEL: C72,D82,D84)

\section{List of Symbols}

Symbol

$\mathrm{O}$

0

1

1
Identification

Capital letter oh

Zero

Number one

Letter ell 
Abstract: The Ultimatum game is simple and this facilitates its use in the study of predictions of game theory. Experimental evidence suggests that it does not predict individual behavior well, unless individuals gain welfare from fairness in transactions, or have expectations about some wider game. Our model excludes any notion of fairness by including (potential) rivalry in transactions. In this game the proposer's expectations yield outcomes that are consistent with experimental evidence. Offers can be large or small, with none in an intermediate range. The consequent distribution appears in Dictator game experiments. Our model explains how it is generated by expectations.

(JEL: C72,D82,D84)

\section{Introduction}


The ultimatum game is a division game of a fixed sum between two players. One player offers the other a proportion of the total sum and the other either accepts it, in which case the sum is allocated between the players in the proportion offered; or rejects it and neither player gets anything. In its pure form the game is played only once and there is thus no bargaining. The subgame-perfect equilibrium to the game where the players are rational and only care about their monetary reward, is for the proposer to offer the smallest proportion of the total pie consistent with the unit of account and for the potential recipient to accept (Rubenstein (1982) and Stahl (1972)). The first experimental evidence is attributed to Guth et al (1982) which found that offers were much closer to a proportion of $50 \%$ than the theory predicts. The survey by Thaler (1988) also concludes that the experimental evidence is not in accord with noncooperative-game-theory predictions when preferences are defined without incorporating some notion of fairness in transactions. Using an experiment with a fictitious pie to be divided, Ortona (1991) provides conflicting evidence. Potential recipients who identified the independent-utility rational agent's decision still did not make this decision, but exhibited behavior consistent with some non-independence of utility. Proposers who apparently understood the game did seem to offer a lower amount than those whose understanding was weaker. Overall, while a small proportion of proposers seem to make very small offers, a significant proportion make offers of close to $50 \%$ of the total pie.

Two central potential explanations for the departures of experimental outcomes from game theoretic predictions are that the proposer is concerned about fairness, and that the proposer has beliefs about matters which may include the possibility of the offer 
being rejected, the possibility of future experiments and other player interactions, and beliefs about the nature of the game as represented by the experiment.

Fairness may explain the experimental results directly. Bolton (1991) develops the Ochs and Roth (1989) suggestion of interacting utility functions, and proposes a model in which distributional considerations appear in the bargainers' objective functions. If fairness is defined to be the situation where agents gain welfare from their own payoff and lose welfare from unequal shares of the pie, then the greater the weight placed on fairness, the greater the offer. Rabin (1993) argues that fairness goes further than altruism, in that it entails preferences in which, based on their beliefs, "People like to help others who are helping them and to hurt those who are hurting them". He calls the equilibria of games that entail these preferences and beliefs "fairness equilibria" and shows that they lead to outcomes that are consonant with the experimental evidence that suggests offers are larger than those that result from standard ultimatum games.

However, interdependence need not be attributed to fairness. It may be that the ultimatum game played by participants for small stakes, as in experiments, should be viewed as a subgame of a wider actual game among participants. Where reputation matters for the larger game, it may be rational for players to not reveal their selfishness or type in this subgame and hence, in particular experiments, appear as though they support some concept of fairness. While appearing to be fair in a game with low payoffs may not improve one's reputation, appearing to be selfish may have strong negative repercussions in the larger game. 
Hoffman et al (1994) stress the second explanation of the experimental data: the role of beliefs. First there is the perception of the proposer that the potential recipient may care about some aspect of the transaction separately from the income gained; as would be the case if reputation in a wider game matters. If the game is among a cohort of students, for example, the experimental game is of small importance relative to the lifetime games that take place among members of the cohort. Secondly, experimental design may carry with it the generation of expectations about a variety of other factors: examples include the possibilities of future experimental games and that the experimenter is, in fact, examining fairness. Hoffman et al (1994) suggest that these beliefs are important. They find that offers are much more in agreement with standard theory when the experimental subjects are anonymous and they know that the anonymous experimenter cannot link answers to subjects.

The two explanations of the data are fundamentally different. In the presence of fairness the proposer's utility function gives some weight to the other player's welfare and more than a minimal offer will be made irrespective of the second player's preferences. In contrast, if it is beliefs which are operative an proposer with no interest in fairness may nevertheless make a considerable offer.

In this paper we propose a game in which players are selfish and explore the role of beliefs about other players in determining the offer. Expectations are formed via a probability distribution over the magnitude of a rivalry parameter in the utility function of the players. The use of rivalry means that fairness is explicitly ruled out: emphasizing that it is solely beliefs that can be the source of larger than minimal offers. 
Whether rivalry is more appropriate than fairness will depend upon one's hypothesis about agent preferences. If utility functions are to be interdependent there would seem to be as much a place for a relative income concept, such as rivalry, as for fairness. The agents may or may not be rivalrous in our model, but the proposer, even if not rivalrous, is concerned about the rivalry parameter of the person with veto power. Thus, the rational proposer forms expectations about the possibility of rejection of any offer, given the population distribution of the rivalry parameter. The proposer trades off the low cost of a low offer, against the higher probability of rejection of a low offer. The person with veto power confronts no uncertainty at all: the accept/reject decision is made after the offer is disclosed.

The game is most interesting if the two players are drawn from the same population, and if there is a finite probability that the proposer's utility function has no interdependence with the other player's utility function. We characterize optimal solutions in terms of the parameters of the distribution function, and the utility function of the proposer. We conclude that for a wide class of parameter values it will be rational for some proposers to choose a zero or minimal offer, and for others to choose an offer close to $50 \%$ of the pie. The offer decreases with the proportion of the population which care only about their own wealth, and over this parameter set there is a discontinuity. Given this proportion and a random drawing of agents there may exist proposers who will offer zero and others who offer as much as $40 \%$, say, but none who place offers in the intermediate range $(0,40 \%)$. Even under risk neutrality the model offers a rich explanation of empirical findings. We also show that a risk averse 
extension of our model exhibits the same qualities, and that more risk averse players will make larger offers.

We conclude the paper by examining the implications of uncertainty about the size of the pie and link this to experimental findings. A modification of our approach yields a dictator game model that explains experimental findings of this game well.

In the next section we set out the risk-neutral case, and in Section 3 we examine the situation where the players are risk averse. In the fourth section we describe the nature of the optimal offer from the proposer's perspective, and in the final section we review the implications of different information and game structures. In particular separate cases, uncertainty about the size of the pie is incorporated, and the model is developed for the dictator game: in both cases theory is linked to experimental findings.

\section{The risk neutral game}

Consider the following game involving two players and \$10. First, player 1 chooses a number, $y \in[0,10]$ which is the proposed payoff to Player 2 (for analytical convenience we will consider all real numbers from zero to ten). Player 2 then announces either yes or no. The payoffs to the players are then given by the following figure, where $(\mathrm{x}, \mathrm{y})$ are the payoffs to Players 1 and 2 respectively: (Figure 1)

Assumption 1. The game is common knowledge amongst the two players. 
Now, individual rationality and independent utilities would seem to imply that Player 2 will say yes to any offer, $\mathrm{y}>0$, and will be indifferent between yes and no for $\mathrm{y}=0$. Hence, the unique subgame perfect Nash equilibrium for the game is $\{\mathrm{y}=0, y e s\} .^{1}$ In particular, this equilibrium should be independent of the total amount of cash distributed (in this case $\$ 10$ ) and whether Player 2 knows this number or not. However, as we have indicated, experimental evidence would seem to suggest that Player 1 does not generally offer $\mathrm{y}=0$, or even $\mathrm{y}=\varepsilon$, where $\varepsilon$ is the smallest positive monetary unit available (for example, if the $\$ 10$ is represented by 10 one dollar notes, then $\varepsilon=\$ 1$ ). In fact, it would appear that on many occasions Player 1's offer is closer to $y=5$ than $y=$ 0. We explain this empirical observation by arguing that Player 2's knowledge of the total amount to be distributed introduces the feasibility of making decisions on the basis of rivalry where players covet their own share and its excess over the remainder; if $y$ is too low Player 2 will say no, and Player 1 knows this. The expected cost to Player 1 of a potential rejection will affect the offer. Neither player may actually covet the share the other person gets, but the possibility of Player 2 gaining welfare from rivalry may be sufficient to induce Player 1 to offer more than $\varepsilon$.

Assumption 2 (risk neutrality and rivalry). Let $\mathrm{x}$ and $\mathrm{y}$ be the payoffs to Players 1 and 2 respectively. Utility functions for the two players are then given by:

$$
\mathrm{U}^{1}=\mathrm{x}+\mathrm{a} \cdot[\mathrm{x}-\mathrm{y}], \text { and } \mathrm{U}^{2}=\mathrm{y}+\mathrm{b} \cdot[\mathrm{y}-\mathrm{x}]
$$

where $\{a \geq 0, b \geq 0\}$ capture the players' attitudes towards the distribution of the total payoff. 
These preferences are interdependent in that they admit transaction rivalry. Each player gains welfare from their own payoff and its excess over the other player's payoff from the game. This specification could arise from a form of the relative income hypothesis in which agents care about their gain from transactions and its relationship to that of the persons they deal with. The case where there is a direct concern for fairness may be represented by $\{\mathrm{a} \leq 0, \mathrm{~b} \leq 0\}$ in which case player 1 may offer much more than $\mathrm{y}=0$; but we do not analyze this case. Because the game concerns additions to each player's wealth, actual player-wealth can enter as a constant or in the determination of $\{a, b\}$ without affecting the analysis which follows.

Assumption 3. Player 1 cannot observe b. However, Player 1 knows that $b$ is drawn randomly from a population characterized by $\operatorname{Prob}[\mathrm{b}<0]=0$, and $\operatorname{Prob}\left[\mathrm{b} \leq \mathrm{b}^{\prime}\right]=1-\mathrm{c} \cdot \mathrm{e}^{-\mathrm{b}^{\prime} \mathrm{d}}, \forall \mathrm{b}^{\prime}>0$, where $\mathrm{c} \in[0,1]$, and $\mathrm{d}>0$.

Assumption 3 admits the possibility that both agents are drawn from the same population. The drawings are assumed to be independent so that distribution of Player 2 preference parameters, $b$, is unaffected by the proposer's preference parameter a. Under this interpretation, $\operatorname{Prob}[\mathrm{b}=0]=1-\mathrm{c}$ represents the proportion of the population who do not care about the income of others. The parameter $d$ determines the distribution of the parameter $b>0$ over the remainder of the population. This specification of the cumulative density function allows characterization of equilibria in terms of comprehensible parameters of this function. Now, Player 2 will accept the offer y if and only if $y+b \cdot[y-x] \geq 0$, that is, if and only if $b \leq b(y)$, where 


$$
\frac{\mathrm{y}}{10-2 \cdot \mathrm{y}} \equiv \mathrm{b}(\mathrm{y})
$$

Hence, for $y \in[0,5)$, this critical value of $b$ is a differentiable monotonic increasing function of $\mathrm{y}$. Equivalently, Player 1 can choose a probability of acceptance - a value of $\mathrm{b}$ - and then calculate the value of the offer

$$
y(b)=\frac{10 \cdot b}{1+2 \cdot b}
$$

that will achieve this probability .

Drawing on (1.1), the probability of Player 2 saying yes is $\left[1-\mathrm{c} \cdot \mathrm{e}^{-b d}\right]$, and so the expected utility of Player 1 can be expressed as a function of this critical value of $b$ :

$$
\mathrm{EU}^{1}=\mathrm{F}[\mathrm{a}, \mathrm{b}, \mathrm{c}, \mathrm{d}] \equiv \mathrm{g}[\mathrm{a}, \mathrm{b}] \cdot\left[1-\mathrm{c} \cdot \mathrm{e}^{-\mathrm{bd}}\right],
$$

where, from $(1.1), g[a, b] \equiv x+a \cdot[x-y]=\frac{10 \cdot[1+a+b]}{1+2 \cdot b}$.

Player 1, after observing [a, c, d], will choose $b \in[0, \infty)$ to maximize $F[a, b, c, d]$. Let $b^{*}[\mathrm{a}, \mathrm{c}, \mathrm{d}]$ (and equivalently, $\mathrm{y}^{*}[\mathrm{a}, \mathrm{c}, \mathrm{d}]$ ) be the solution to this problem, then the existence of the solution is guaranteed by:

Proposition 1. Given that Assumptions 1-3 hold and the population parameters $[\mathrm{c}, \mathrm{d}], \mathrm{y}^{*}[\mathrm{a}, \mathrm{c}, \mathrm{d}]$ is a continuous non-increasing function of a, except for a critical value of a when $y^{*}[\cdot]$ is non-unique ( and so not a function). 
The proof of this and subsequent propositions are relegated to the Appendix 1. They are established in terms of the optimal $b^{*}[a, c, d]$, and the statement of the lemmas uses (1.2) to translate them to the optimal offer, $y^{*}[a, c, d]$. The lemma justifies the general proposition that Player 1's placing increasing weight on her reward relative to that of Player 2 - that is, increasing a - will not engender larger offers. Before commenting on the solution relative to parameter subsets we establish further properties of the optimal offer.

Proposition 2. Suppose Assumptions 1-3 hold, then given the population parameter $\mathrm{d}$, and Player 1's rivalry parameter, a, $\mathrm{y}^{*}[\mathrm{a}, \mathrm{c}, \mathrm{d}]$ is a continuous non-decreasing function of $\mathrm{c}$, except for a critical value of $\mathrm{c}$ when $\mathrm{y}^{*}[\mathrm{a}, \mathrm{c}, \mathrm{d}]$ is non-unique (and so not a function).

Thus where the optimal offer is a function it is nondecreasing in the proportion of the population which does care about the payment the other player receives. The parameter space that yields the discontinuity is specified in the following proposition.

Proposition 3. Given Assumptions 1-3 and the parameter a, then

(i) if $\mathrm{d}<\frac{2}{1+\mathrm{a}}, \exists \mathrm{c}$ yielding a discontinuity for $\mathrm{y}^{*}[\mathrm{a}, \mathrm{c}, \mathrm{d}]$, while for

$$
\mathrm{d} \geq \frac{2}{1+\mathrm{a}}, \mathrm{y}^{*}[\mathrm{a}, \mathrm{c}, \mathrm{d}] \text { is a continuous function of } \mathrm{c},
$$

(ii) if $\mathrm{d}<\frac{2}{1+\mathrm{a}}, \exists\left[\mathrm{c}^{\prime \prime}, \mathrm{c}^{\prime}\right]$, with $1>\mathrm{c}^{\prime}>\mathrm{c}^{\prime \prime}$, such that for $\mathrm{c} \in\left(\mathrm{c}^{\prime \prime}, \mathrm{c}^{\prime}\right), \exists \mathrm{b}>0$

$$
\text { yielding } \mathrm{F}_{\mathrm{b}}[\mathrm{a}, \mathrm{b}, \mathrm{c}, \mathrm{d}]=0 \text { and } \mathrm{F}_{\mathrm{bb}}[\mathrm{a}, \mathrm{b}, \mathrm{c}, \mathrm{d}]>0 \text {. }
$$


If the probability mass of the distribution function over positive rivalry parameters that is, $\mathrm{p}\left(0<\mathrm{b} \leq \mathrm{b}^{\prime}\right)$ for all $\mathrm{b}^{\prime}$ - is sufficiently small and Player 1's rivalry parameter is small then the turning point at a positive offer will in fact minimize expected utility.

To describe the offers more precisely we need

Proposition 4: For any given values of [ a, c, d] the expected utility of Player 1, $\mathrm{EU}=\mathrm{F}(\mathrm{a}, \mathrm{b}, \mathrm{c}, \mathrm{d})$, has at most one local maximum $\mathrm{b} \in(0, \infty)$.

and its

Corollary: If there exists some $\mathrm{b}^{*}>0$ such that $\mathrm{F}(\mathrm{a}, ., \mathrm{c}, \mathrm{d})$ has a local maximum at $\mathrm{b}^{*}$, and if $\mathrm{F}(\mathrm{a}, 0, \mathrm{c}, \mathrm{d})=\mathrm{F}\left(\mathrm{a}, \mathrm{b}^{*}, \mathrm{c}, \mathrm{d}\right)$ then the pair $\left\{0, \mathrm{~b}^{*}\right\}$ are the only global maxima of $\mathrm{F}(\mathrm{a}, ., \mathrm{c}, \mathrm{d})$.

that follows immediately. Our establishment of the reported graphs of the offers use the following

Proposition 5: Given any $d<2$, there exists a nonempty set $\left(c_{2}(d), c_{1}(d)\right)$ and an $a^{*}$ such that for every $\mathrm{c} \in\left(\mathrm{c}_{2}(\mathrm{~d}), \mathrm{c}_{1}(\mathrm{~d})\right) \mathrm{F}\left(\mathrm{a}^{*}, ., \mathrm{c}, \mathrm{d}\right)$ has, exactly two global $\operatorname{maxima}\left\{0, b^{*}>0\right\}$. 
A situation with a nonunique optimal offer $\left\{y^{*}=0, y^{*}>0\right\}$ is described in Figure 1. It illustrates the unique a, given $\{\mathrm{c}, \mathrm{d}\}$, such that Player 1 will be indifferent between offering nothing and a positive amount. For any $\{\mathrm{c}, \mathrm{d}\}$ there is an a such that the optimal offer of Player 1 is not unique. It is a consequence of the tradeoff between offering an amount that has a high probability of acceptance and her preference for a large share of the pie. Even when her preference is over $\mathrm{x}$ only $(\mathrm{a}=0.0)$, she is concerned about whether or not the offer will be acceptable and hence may make a positive offer. For certain configurations of $\{c, d\}$ she will be indifferent between making a positive offer or a zero offer.

Because both players are drawn from the same distribution we can calculate the proportion of zero offers that would be observed in a large number of games played by players drawn from this distribution. In the case of Figure 2, those proposers with a $\geq$ $\mathrm{a}^{*}=.8227$ will offer zero. The proportion of zero offers is then $\mathrm{p}\left(\mathrm{y}^{*}=0\right)=1-\mathrm{F}(.8227)=$ 0.45. The proportion making positive offers will be 0.55 . (Figure 2)

Prior to a more detailed characterization of the optimal offer we relax the assumption that agents are risk neutral.

\section{Risk Aversion}

Consider the case where the players are risk averse and the form of the distribution function is that specified above. We assign the utility functions: 
Player 1: $\mathrm{U}^{1}=\mathrm{U}[\mathrm{x}+\mathrm{a} \cdot(\mathrm{x}-\mathrm{y}), \mathrm{q}]$

Player 2: $\mathrm{U}^{2}=\mathrm{U}\left[\mathrm{y}+\mathrm{b} \cdot(\mathrm{y}-\mathrm{x}), \mathrm{q}^{*}\right]$.

Again, the probability that $b \leq b^{\prime}$ is given by $1-c \cdot e^{-b ' d}$, where $c \in(0,1]$, and $d>0$. The variable $\mathrm{q}$ (and $\mathrm{q}^{*}$ ) is a scale of risk aversion. The closer $\mathrm{q}\left(\mathrm{q}^{*}\right)$ is to 1 , the more riskneutral Player 1 (Player 2) becomes. Each player is drawn from an identical joint distribution of $\mathrm{b}(\mathrm{a})$ and $\mathrm{q}\left(\mathrm{q}^{*}\right)$ the cumulative marginal distribution for $\mathrm{b}$ being $\mathrm{F}(\mathrm{b})=1$ - c.e-b'd as formerly.

Assumption 4. U: $\mathbf{R} \times(0,1) \rightarrow \mathbf{R}$ is $\mathrm{C}^{2}$ and satisfies the following conditions:

(i) $\mathrm{U}[0, \mathrm{q}]=0, \forall \mathrm{q} . \mathrm{U}[\mathrm{w}, \mathrm{q}] \rightarrow \mathrm{w}$ as $\mathrm{q} \rightarrow 1$,

(ii) $\mathrm{U}_{1}[\mathrm{w}, \mathrm{q}]>0, \mathrm{U}_{11}[\mathrm{w}, \mathrm{q}]<0, \forall(\mathrm{w}, \mathrm{q})$,

(iii) $[\mathrm{w}-5] \cdot\left\{\mathrm{U}_{1}[\mathrm{w}, \mathrm{q}]^{2}-\mathrm{U}_{11}[\mathrm{w}, \mathrm{q}] \cdot \mathrm{U}[\mathrm{w}, \mathrm{q}]\right\}<\mathrm{U}_{1}[\mathrm{w}, \mathrm{q}] \cdot \mathrm{U}[\mathrm{w}, \mathrm{q}], \forall(\mathrm{w}, \mathrm{q})$,

and

(iv) $\mathrm{U}_{1}[\mathrm{w}, \mathrm{q}] \cdot \mathrm{U}_{2}[\mathrm{w}, \mathrm{q}]<\mathrm{U}_{12}[\mathrm{w}, \mathrm{q}] \cdot \mathrm{U}[\mathrm{w}, \mathrm{q}], \forall(\mathrm{w}, \mathrm{q})$.

This assumption specifies sufficient restrictions on preferences for the results which follow: they can be relaxed. Assumptions 4(i) and 4(ii) are standard, and assumption 4(iii) is implied by sufficiently large relative risk aversion, but assumption 4(iv) has a weaker behavioural interpretation. ${ }^{2}$ To illustrate the assumptions, we point out that while the constant absolute risk aversion utility function does not meet Assumption 4, but the utility function $U[y+b \cdot(y-x), q]=[y+b \cdot(y-x)]^{q}$ does satisfy it. 
The problem for Player 1 , with parameters $(a, q)$ is to choose $b \geq 0$, in order to maximize the expected utility

$$
\mathrm{F}[\mathrm{a}, \mathrm{b}, \mathrm{c}, \mathrm{d}, \mathrm{q}] \equiv \mathrm{U}[\mathrm{g}(\mathrm{a}, \mathrm{b}), \mathrm{q}] \cdot\left[1-\mathrm{c} \cdot \mathrm{e}^{-\mathrm{bd}}\right],
$$

where, again, $g(a, b) \equiv \frac{10 \cdot[1+a+b]}{1+2 \cdot b}$. This definition of $g($.$) follows from the fact that$ there is no uncertainty confronting Player 2. He knows Player 1's offer and his own (b, $\left.q^{*}\right)$; thus he will accept any offer which satisfies (1.1).

The basis of the following proposition is established in the Appendix 1 and by the application of (1.2).

Proposition 6: If $\mathrm{c}>\frac{4-\mathrm{d}}{4+\mathrm{d}}$, then $\mathrm{y}^{*}[\mathrm{a}, \mathrm{c}, \mathrm{d}, \mathrm{q}]>0$ is a well-defined function.

Further, it is non-increasing in both a and q. For these population parameters, $\mathrm{y}^{*}[\cdot]$ is non-decreasing in c, although not necessarily monotonic in $\mathrm{d}$.

This proposition characterizes the optimal offer $y^{*}$, over a subset of the domain of that function. Over this subset the optimal offer has the same qualitative properties irrespective of the presence of risk aversion. 


\section{The Optimal Offer}

The optimal offer entails trading off the reduction in utility associated with paying Player 2 more upon acceptance, and the concomitant increase in the probability that the offer will be accepted. The optimal offer will depend upon $\{\mathrm{c}, \mathrm{d}\}$ and the rivalry parameter of the proposer. For low enough $\mathrm{c}$ this offer will be zero, but it will increase if $\mathrm{c}$ is increased sufficiently. ${ }^{3}$ While the offer may increase smoothly from zero, there is a finite set of $\{a, c, d\}$ such that increases in c have no effect on the optimal offer (of zero) until a certain point when there is a multiple solution (zero and a much larger offer). Beyond this point the offer switches from zero to a significant offer (as large as $40 \%-50 \%$ of the pie) as the proportion of persons who covet the excess of their gain over that of the other person, c, increases.

To illustrate this process we present diagrams of the expected utility of Player 1 , the proposer, when $U[x+a \cdot(x-y), q]=[x+a \cdot(x-y)]^{q}$. We assume that $d=1$ and that the proposer's welfare is not affected by that of Player 2 , that is, $a=0$, and we graph the objective function for various levels of risk aversion, q. Expected utility is plotted for offers less than 5 because it approaches minus infinity as y approaches 5 . Since low q represents strong risk aversion, Figure 3 illustrates that over the range of c's graphed the optimal offer is just below $50 \%$.

In Figure 4 the level of risk aversion is less than that of Figure 3 . The change has left the qualitative nature of the optimal choice the same, but for low values of $\mathrm{c}$ the extra welfare from making the optimal choice is small compared to the significantly risk- 
averse case of Figure 3. The nature of the change continues when moving to Figure 5 where Player 1 is mildly risk averse. We see that at this mild level of risk aversion, for low values of $\mathrm{c} \mathrm{y}^{*}=0$ will be chosen, and that for higher values of $\mathrm{c}$ offers close to 5 will be made.

Thus, generally higher risk aversion leads to higher offers. This is intuitively plausible in that as risk aversion increases, the marginal utility of wealth declines; altering the balance between the decrement in utility from an increased offer, and the increment in the probability of acceptance from a higher offer. The effect of this for increased risk aversion, as we have defined it, is to predicate higher offers. (Figures $3,4, \& 5$ ).

\section{Enriching the Information Structure: Theory and Experiment}

The expanding literature about the ultimatum game is focussed on explaining experimental results by the information structure of the game and the concomitant perceptions of the players. Variations such as creating uncertainty about the size of the

pie (Straub and Murnighan (1995)), changing the amount and type of information of the responder (Croson 1996)) have been used to elucidate the perceptions of players and their responses.

In addition, the dictator game has been used to examine the role of the experimental setting in affecting experimental outcomes (Hoffman et al (1994), Hoffman et al (1996)). For this purpose it possesses the advantage over the ultimatum game of eliminating strategic behaviour from the game itself. In this game the dictator decides 
(dictates) the share of the pie and the second player has no say in whether or not the share transfer is implemented, but does receive the residual.

These two parallel experimental approaches of changing the information structure of the game in various ways and eliminating strategic behavior by using the dictator game are leading to advances in our comprehension of experimental results. However, there remains a need to link experimental outcomes to theoretical frameworks.

In this section we first review additional results from our model about what might occur when the size of the pie is uncertain, and link these to the experimental literature. We then re-cast our model to capture the essence of the dictator game. In both cases we show that our models have explanatory power for reported experimental results.

Uncertainty and the Ultimatum Game: We use our model to explore the implications of uncertainty about the size of the pie that is to be shared. Despite the simplicity of the ultimatum game there is a set of rich information structures that we can consider. We summarize the games and selective predictions below, under risk neutrality and where Player 2 knows the distribution from which the size of the pie is taken. The basis for the analysis is set out in Appendix 2.

1. Common Information. Both players know the distribution of an uncertain pie but neither player knows the realized value until the game is over: thus Player 1's offer reveals no information. In this game the offer is bounded above by the smallest feasible pie.

2. Private Information but no updating. Player 1 is told the pie size but Player 2 does not use the offer to update his assessment of the size. This can be viewed as a case 
of unsophisticated play, or a game of bounded rationality whereby it does not pay Player 2 to carry out the updating calculus. In this game, for any Player 1, a lowering of the mean of the distribution will lower the optimal offer.

3. Private Information with the choice of revelation. Player 1 observes the size of the pie and has the option of revealing this value to Player 2. In this case Player 1 always reveals, and hence the game is the one of common knowledge that forms our basic model.

4. Private Information with updating. When Player 1 sees the size of the pie and then announces her offer, Player 2 uses this information to update his prior (conditional probability) as to the size of the pie. In the case where the pie can take on one of only two values we report an example where two equilibria occur.

5. Private Information with updating: a mean preserving spread. Here we expand the previous example by instituting a mean preserving spread to the uncertain size of the pie. For the case of one of the equilibria we show that the effect of an increase in uncertainty on the probability of a zero offer depends upon how this uncertainty increase is achieved. While an increase in uncertainty raises the probability of zero offers in a range of circumstances, where the change results from a decrease in the lower pie size and a decrease in the probability of its occurrence (i.e. an increase in the probability of the high pie level) the change in probability can dominate decision making over that of the lower-bound pie size and result in higher zerooffer probabilities.

Certain of these games have structures that are quite close to those reported for some experimental games. For example, the question posed in the experiment of Croson 
(1996) is similar to that of Case 2. Croson's (1996) lowering of the mean of the distribution of the pie yields reduced average-offer outcomes that are qualitatively in agreement with case 2 of our model.

Case 5 can be related to Straub and Murnighan $(1995,361)$ who conclude on the basis of experimental evidence that people will accept very low ultimatum offers when they do not know how much is being divided. Their comparison is to compare choice under uncertainty and certainty. In case 5 we show that this response to an increase in uncertainty is also a prediction of our model when uncertainty is increased but that it may not always occur: the outcomes may be sensitive to the specification of changed uncertainty. $^{5}$

Another characteristic of our model that was explored was increased uncertainty about the respondent's preference parameter. However, it has no experimental counterpart and hence we do not report it. ${ }^{6}$

The Dictator Game: Hoffman et al (1994) and Hoffman et al (1996) conduct experiments with the dictator game. Their results mesh very tightly with those of this paper in two ways. Firstly, the dictator experiments that are designed to effect complete anonymity of the players and the experimenter yield predictions which are much closer to those of games with self-contained selfish players, than does this game when the experimenter is not anonymous. Increases in anonymity reduce the role of expectations in the game.

The second and striking finding with respect to these dictator game experiments is that many of them exhibit offer distributions with bi-modal tendencies (see Hoffman et al (1994) and Hoffman et al (1996), for example); some strongly. Although this game 
does not entail strategy, using our result that expected utility may generate a bi-modal distribution (albeit in the ultimatum game), the dictator game results do suggest that the agents were forming expectations about some aspect of the game structure. In our ultimatum game model a bi-modal offer distribution will arise for a particular trade-off between the reduction in utility yielded by an increment in the offer and the concomitant increase in the probability of acceptance. ${ }^{7}$ We show below how these conclusions are confirmed in a our model appropriately modified for the dictator game.

Hoffman et al (1996) go on to conduct dictator game experiments that place increasing social distance between the paired subjects. ${ }^{8}$ If the decision making agent is led to believe that the other agent is from the same community, and hence that future interaction may occur, that agent makes a higher offer. ${ }^{9}$ In the case of experiments conducted with a cohort of university students, for example, there is likely to be some probability of (potential) future transactions between them, and the reputation for opportunistic behavior signaled in the dictator game may affect the outcome of the dictator game. From another point of view, if there is any possibility of future interaction, experimental dictator games offer a low-cost way of signaling one's reputation for opportunism. For this to be an important factor, there is no need for, in future transactions, respondents of past games to be precisely matched with the proposers: information that one party participated in the dictator game as proposer may affect behavior depending upon the experience of the respondent.

In sum, bi-modal share (offer) outcomes appear in the dictator game experiments, and the socially more distant dictators are from residual recipients, the higher is the share that the dictator takes. We now modify our model to one which precisely captures the 
dictator game, but which allows for the possibility of future interaction with the residual recipient.

At the date the dictator game is played, first Player 1 must share a pie, of size A, by offering Player 2 an amount y. Second, Player 2 then says either content or not-content (rather than accept or not-accept as in the ultimatum game). Player 2 is content if and only if his welfare,

$$
\mathrm{U}^{2}=\mathrm{y}+\mathrm{b} \cdot[\mathrm{y}-\mathrm{x}] \geq 0
$$

To ensure that Player 2 tells the truth we assume that there is a small cost, $\varepsilon>0$, to lying.

Finally, if Player 2 says content then Player 1 receives an amount, $\mathrm{z}$, while if she says not-content Player 1 receives 0 ( $\mathrm{z}$ is destroyed). As $\mathrm{z}$ is not contestable it does not enter into Player 2's utility function. That is, Player 2 is happy for Player 1 to receive $\mathrm{z}$ if and only if she is content. If he feels that he has been treated badly by Player 1 (and so he says not-content), and he can punish Player 1 - at no cost to himself - then he will do so. Yet another view of this arrangement is that as a result of having been the residual recipient, Player 2's assessment of Player 1's potential opportunism is determined by whether or not he was content. If Player 1 is deemed to be opportunistic under this criterion then Player 2's (bargaining) response is such that Player 1 expects to lose $\mathrm{z}$ in a future transaction. Thus, total welfare for Player 1 includes expected future gains, $\mathrm{z}$, if Player 2 is content, and 0 otherwise. The amount $\mathrm{z}$ is the (present value of) an expected payoff in the future that would result from a future potential meeting/transaction between proposer and a contented responder. ${ }^{10}$ 
Now Player 2 is content with the offer, $y$, if and only if $U^{2}=[1+b] \cdot y-b \cdot[A-y] \geq 0$, or $\mathrm{b} \leq \mathrm{y} \cdot[\mathrm{A}-2 \cdot \mathrm{y}]^{-1}$, where $\mathrm{A}$ is the total size of the pie, and hence this becomes the criterion for whether Player 2 is content and Player 1 can expect to get $\mathrm{z}$. The welfare of Player 1 is thus the expected payoff

$$
\mathrm{U}^{1}=[1+\mathrm{a}] \cdot \mathrm{A}-[1+2 \cdot \mathrm{a}] \cdot \mathrm{y}+\mathrm{z} \cdot\left\{1-\mathrm{c} \cdot \mathrm{e}^{-\mathrm{dy} /[\mathrm{A}-2 \mathrm{y}]}\right\}
$$

and an example is graphed in Figure 6 for various values of z. (Figure 6)

The graphs of Figure 6 show that as the expected payoff from a future interaction grows the optimal offer switches from zero to one that is close to half the pie. Thus there exist parameters of our model that will yield the bi-modal distributions observed in dictator game experiments. In parallel with the ultimatum game, they arise in the trade-off between decreased utility at the time of the game and the increased probability of future positive welfare that occurs when the share taken by the dictator is decreased.

An increase in $\mathrm{z}$ can take place because either the actual payoff has increased or because the probability of future interaction between the players has increased. A decrease in $z$ would occur with increasing social distance between the players; it lowers the likelihood of their transacting in the future, and it draws lower shares for the residual recipient.

These results proffer theoretical confirmation of the experimental findings of Hoffman et al (1996) that behavior is selfish but affected by the extent to which the other agent is thought to be from the same community. Expectations and inference, rather than fairness, play a critical role in determining the outcome of the game. 
In the ultimatum game, responding subjects may cite "unfairness" of the offer as the explanation for why they did not accept it. Even if this accurately depicts the respondent's view, it need not mean that this person expects all players to be altruistic. The term "unfair" could be applied to unfulfilled rivalistic expectations.

In more general settings where evolutionary change is possible, populations of altruistic agents can be invaded by self-interested agents who succeed at the expense of altruistic agents. Games with populations of altruistic agents have to explain why the outcomes represent long term equilibria in the presence of evolution. Our rivalrous agents resist invasion and yet can make generous offers. 


\section{Appendix 1: Propositions}

\section{(i) Proposition 1}

Suppose Assumptions 1-3 hold. Given the population parameters, [c, d], y*[a, c, d] is a continuous non-increasing function of a, except for a critical value of a when $\mathrm{y}^{*}[\cdot]$ is non-unique ( and so not a function).

Proof: Let

$$
a[b, d] \equiv \frac{1+b \cdot d \cdot[1+b]-e^{b d}}{e^{b d}-[1+b \cdot d]}, c[b, d] \equiv \frac{1+b \cdot d \cdot[1+2 \cdot b]-e^{b d}}{e^{-b d+b \cdot d \cdot[1+2 \cdot b]-1}}
$$

and $\mathrm{c}[\mathrm{d} ; \mathrm{a}[\mathrm{b}, \mathrm{d}]=0] \equiv \mathrm{c}[\mathrm{b}, \mathrm{d}]$ when $\mathrm{b}$ is a function of d defined by $\mathrm{a}[\mathrm{b}, \mathrm{d}]=0$, then

(i) for $\mathrm{d}<2$, and $\mathrm{c} \in[0, \mathrm{c}[\mathrm{d} ; \mathrm{a}=0]], \mathrm{y}^{*}[\mathrm{a}, \mathrm{c}, \mathrm{d}]=,0 \forall \mathrm{a} \geq 0$,

(ii) for $\mathrm{d}<2$ and $\mathrm{c} \in\left[\mathrm{c}[\mathrm{d} ; \mathrm{a}=0], \frac{4-\mathrm{d}}{4+\mathrm{d}}\right), \exists \mathrm{a}^{*} \equiv \frac{\mathrm{c} \cdot \mathrm{d}-[1-\mathrm{c}]}{2 \cdot[1-\mathrm{c}]-\mathrm{c} \cdot \mathrm{d}} \in[0, \infty)$, such that for $\mathrm{a}>\mathrm{a}^{*}, \mathrm{y}^{*}[\mathrm{a}, \mathrm{c}, \mathrm{d}]=0$, and for $\mathrm{a}<\mathrm{a}^{*}, \mathrm{y}^{*}[\mathrm{a}, \mathrm{c}, \mathrm{d}]$ is a continuous decreasing function of $a$. When $a=a^{*}$, there are two optimal offers $y$; at this point $y^{*}[\cdot]$ jumps from 0 to a positive value.

(iii) for $\mathrm{d}<2$, and $\mathrm{c} \in\left[\frac{4-\mathrm{d}}{4+\mathrm{d}}, \frac{2}{2+\mathrm{d}}\right)$, then $\mathrm{y}^{*}[\mathrm{a}, \mathrm{c}, \mathrm{d}]=0$ for $\mathrm{a} \geq \mathrm{a}^{*}$, while for $\mathrm{a}$ $<\mathrm{a}^{*}, \mathrm{y}^{*}[\mathrm{a}, \mathrm{c}, \mathrm{d}]$ is a continuous decreasing function of $\mathrm{a}$,

(iv) for $\mathrm{d} \geq 2$ and $\mathrm{c} \in\left[0, \frac{1}{1+\mathrm{d}}\right), \mathrm{y}^{*}[\mathrm{a}, \mathrm{c}, \mathrm{d}]=0, \forall \mathrm{a}$, 
(v) for $\mathrm{d} \geq 2$ and $\mathrm{c} \in\left[\frac{1}{1+\mathrm{d}}, \frac{2}{2+\mathrm{d}}\right)$, then $\mathrm{y}^{*}[\mathrm{a}, \mathrm{c}, \mathrm{d}]=0$ for $\mathrm{a} \geq \mathrm{a}^{*}$, while for $\mathrm{a}<$ $a^{*}, y^{*}[a, c, d]$ is a continuous decreasing function of a; where

$$
a^{*}=\frac{c \cdot d-[1-c]}{2 \cdot[1-c]-c \cdot d} \text {, and }
$$

(iv) for $\mathrm{c} \in\left[\frac{2}{2+\mathrm{d}}, 1\right], \mathrm{y}^{*}[\mathrm{a}, \mathrm{c}, \mathrm{d}]$ is a continuous decreasing function of $\mathrm{a}, \forall \mathrm{a}$.

The proof uses

Lemma 1. Suppose Assumptions 1-3 hold. Further, suppose $d \geq 2$ or $d \in[0,2)$, and

$$
c \in\left[0, \frac{d \cdot e^{2-d}}{8-d}\right] \cup\left[\frac{4-d}{4+d}, 1\right] . \text { If: }
$$

a) $\mathrm{Fb}[\mathrm{a}, 0, \mathrm{c}, \mathrm{d}]>0$ then $\mathrm{y}^{*}[\mathrm{a}, \mathrm{c}, \mathrm{d}]>0$ is given by $\mathrm{Fb}[\cdot]=0$, and

b) $\mathrm{Fb}[\mathrm{a}, 0, \mathrm{c}, \mathrm{d}] \leq 0$, then $\mathrm{y}^{*}[\mathrm{a}, \mathrm{c}, \mathrm{d}]=0$.

Proof of Lemma 1: first,

$F_{b}[a, b, c, d]=g b(a, b) \cdot\left[1-c \cdot e^{-b d}\right]+c \cdot d \cdot g(a, b) \cdot e^{-b d}$, and

$F_{b b}[a, b, c, d]=g b b(a, b) \cdot\left[1-c \cdot e^{-b d}\right]+2 \cdot c \cdot d \cdot g b(a, b) \cdot e^{-b d}$

$$
-c \cdot d^{2} \cdot g(a, b) \cdot e^{-b d}
$$

where $g(a, b)=\frac{10 \cdot[1+a+b]}{1+2 \cdot b}, g b(a, b)=\frac{-10 \cdot[1+2 \cdot a]}{[1+2 \cdot b]^{2}}$, and

$$
\operatorname{gbb}(a, b)=\frac{40 \cdot[1+2 \cdot a]}{[1+2 \cdot b]^{3}} . \text { Hence, }
$$

$$
F_{b}[a, b, c, d]=\left(\frac{10}{[1+2 \cdot b]^{2}}\right) \cdot\left\{c \cdot d \cdot[1+a+b] \cdot[1+2 \cdot b] \cdot e^{-b d}\right.
$$

$$
\left.-[1+2 \cdot a] \cdot\left[1-c \cdot e^{-b d}\right]\right\}
$$


and $\quad F b b[a, b, c, d]=\left(\frac{10}{[1+2 \cdot b]^{3}}\right) \cdot\left\{4 \cdot[1+2 \cdot a] \cdot\left[1-c \cdot e^{-b d}\right]\right.$

$$
\begin{aligned}
& -2 \cdot c \cdot d \cdot[1+2 \cdot a] \cdot[1+2 \cdot b] \cdot e^{-b d} \\
& \left.-c \cdot d^{2} \cdot[1+a+b] \cdot[1+2 \cdot b]^{2} \cdot e^{-b d}\right\}
\end{aligned}
$$

Notice, for $\mathrm{b}$ large enough, $\mathrm{Fb}_{\mathrm{b}}[\mathrm{a}, \mathrm{b}, \mathrm{c}, \mathrm{d}]<0$. Second, given $\mathrm{Fb}_{\mathrm{b}}[\cdot]=0, \mathrm{Fbb}_{\mathrm{b}}[\cdot] \geq 0$ iff

$$
c \cdot d \cdot[1+2 \cdot b] \cdot e^{-b d} \cdot\{4 \cdot[1+a+b]-2 \cdot[1+2 \cdot a]-d \cdot[1+a+b] \cdot[1+2 \cdot b]\} \geq 0,
$$

iff

$$
2-d \cdot[1+a+b] \geq 0
$$

That is, if $\mathrm{a}+\mathrm{b}>\frac{2-\mathrm{d}}{\mathrm{d}}$, then $\mathrm{F}_{\mathrm{b}}[\cdot]=0$ yields a local maximum. Third, $\mathrm{Fb}_{\mathrm{b}}[\cdot]=0$ iff

$$
c=c[a, b, d]=\frac{[1+2 \cdot a] \cdot e^{b d}}{1+2 \cdot a+d \cdot[1+a+b] \cdot[1+2 \cdot b]} .
$$

Further,

$$
\begin{gathered}
\frac{\partial c[\cdot]}{\partial a}=\frac{d \cdot[1+2 \cdot b]^{2} \cdot e^{b d}}{\{1+2 \cdot a+d \cdot[1+a+b] \cdot[1+2 \cdot b]\}^{2}}>0, \text { and } \\
\frac{\partial c[\cdot]}{\partial b}=\frac{[1+2 \cdot a] \cdot[1+2 \cdot b] \cdot\{d \cdot[1+a+b]-2\} \cdot e^{b d}}{\{1+2 \cdot a+d \cdot[1+a+b] \cdot[1+2 \cdot b]\}^{2}}<0,
\end{gathered}
$$

iff

$$
2-\mathrm{d} \cdot[1+\mathrm{a}+\mathrm{b}]>0 .
$$

Hence,

a) if $\mathrm{d}>2$, then $\mathrm{Fb}_{b}[\cdot]=0$ yields a global maximum, as $2-\mathrm{d} \cdot[1+\mathrm{a}+\mathrm{b}]<0$, $[\mathrm{a}, \mathrm{b}] \in \mathbf{R}^{2}$.

b) if $\mathrm{d}=2, \mathrm{Fb}_{\mathrm{b}}[\cdot]=0$ and $\mathrm{F}_{\mathrm{bb}}[\cdot] \leq 0$ implies $\mathrm{a}=\mathrm{b}=0$, and $\mathrm{c}=\mathrm{c}[\mathrm{a}, \mathrm{b}, \mathrm{d}]=\frac{1}{3}$. 
Now, if $[a, b] \neq[0,0]$, then $c[a, b, d]>\frac{1}{3}$, as $c[\cdot]$ is strictly increasing in both a and $b$.

Hence, $\mathrm{b}^{*}\left[0, \frac{1}{3}, 2\right]=0$. Further, if $\mathrm{c}<\frac{1}{3}$, then $\mathrm{Fb}[\mathrm{a}, 0, \mathrm{c}, \mathrm{d}]<0, \forall \mathrm{a} \geq 0$, if $\mathrm{c} \geq \frac{1}{2}$, then $\mathrm{Fb}[\mathrm{a}, 0, \mathrm{c}, \mathrm{d}]>0, \forall \mathrm{a} \geq 0$, while if $\mathrm{c} \in\left(\frac{1}{3}, \frac{1}{2}\right), \mathrm{Fb}[\mathrm{a}, 0, \mathrm{c}, \mathrm{d}]<0$ if and only if $\mathrm{a}>$ $\frac{3 \cdot c-1}{2-4 \cdot c}$

c) if $\mathrm{d}<2$, then for $\mathrm{a}+\mathrm{b} \leq \frac{2-\mathrm{d}}{\mathrm{d}}, \mathrm{c}[\mathrm{a}, \mathrm{b}, \mathrm{d}]$ is maximized by setting $\mathrm{b}=0$, and $\mathrm{a}=\frac{2-\mathrm{d}}{\mathrm{d}}$ , yielding $\mathrm{c}\left[\frac{2-\mathrm{d}}{\mathrm{d}}, 0, \mathrm{~d}\right]=\frac{4-\mathrm{d}}{4+\mathrm{d}}$, while $\mathrm{c}[\cdot]$ is minimized by setting $\mathrm{a}=0$ and $\mathrm{b}=\frac{2-\mathrm{d}}{\mathrm{d}}$, yielding $\quad c\left[0, \frac{2-d}{d}, d\right]=\frac{d \cdot e^{2-d}}{8-d}$.

d) if $\mathrm{c} \leq \frac{1}{1+\mathrm{d}}$, then $\mathrm{Fb}[\mathrm{a}, 0, \mathrm{c}, \mathrm{d}] \leq 0, \forall \mathrm{a} \geq 0$. If $\mathrm{c} \geq \frac{2}{2+\mathrm{d}}, \mathrm{Fb}[\mathrm{a}, 0, \mathrm{c}, \mathrm{d}]>0, \forall \mathrm{a} \geq 0$, while for $\mathrm{c} \in\left(\frac{1}{1+\mathrm{d}}, \frac{2}{2+\mathrm{d}}\right), \mathrm{Fb}[\mathrm{a}, 0, \mathrm{c}, \mathrm{d}]<0$ if and only if $\mathrm{a}>\frac{\mathrm{c} \cdot[1+\mathrm{d}]-1}{2-\mathrm{c} \cdot[2+\mathrm{d}]}$.

Proof of Proposition 1: first,

$$
\left.\mathrm{Fba}_{\mathrm{b}} \cdot\right]=\left(\frac{10}{[1+2 \cdot \mathrm{b}]^{2}}\right) \cdot\left\{\mathrm{c} \cdot \mathrm{d} \cdot[1+2 \cdot \mathrm{b}] \cdot \mathrm{e}^{-\mathrm{bd}}-2 \cdot\left[1-\mathrm{c} \cdot \mathrm{e}^{-\mathrm{bd}}\right]\right\}
$$

Now, $\mathrm{Fb}_{b}[\cdot]=0$ implies that $\mathrm{a} \cdot\left\{\mathrm{c} \cdot \mathrm{d} \cdot[1-2 \cdot \mathrm{b}] \cdot \mathrm{e}^{-\mathrm{bd}}-2 \cdot\left[1-\mathrm{c} \cdot \mathrm{e}^{-\mathrm{bd}}\right]\right\}+\mathrm{c} \cdot \mathrm{d} \cdot[1+2 \cdot \mathrm{b}] \cdot \mathrm{e}^{-\mathrm{bd}}$ $\left[1-\mathrm{c} \cdot \mathrm{e}^{-\mathrm{bd}}\right]=0$, and so $\mathrm{Fba}[\cdot]<0$ (for $\mathrm{c}<1$, and $\mathrm{b}>0$ ). Hence it follows that when the optimal choice of $\mathrm{b}, \mathrm{b}^{*}[\mathrm{a}, \mathrm{c}, \mathrm{d}]$, is given by $\mathrm{F}_{\mathrm{b}}[\cdot]=0$ and $\mathrm{F}_{\mathrm{bb}}[\cdot]<0, \frac{\partial \mathrm{b}}{\partial \mathrm{a}}<0$. 
All but condition (ii) follow trivially from Lemma 1, combined with the above observation. Notice, when $d=2, c[d]=\frac{4-d}{4+d}=\frac{1}{1+d}$. Further, in conditions (iii) and (v), a* is chosen so as to yield $\mathrm{Fb}_{\mathrm{b}}\left[\mathrm{a}^{*}, 0, \mathrm{c}, \mathrm{d}\right]=0$.

All that remains to be shown, therefore, is that condition (ii) holds and for this it is sufficient to show that if $G[a]=F[a, 0, c, d]-F[a, b(a), c, d]=0$, then $\frac{d G[a]}{d a}>0$, where $\mathrm{b}(\mathrm{a})>0$ is given by $\mathrm{Fb}[\cdot]=0$ and $\mathrm{Fbb}[\cdot]<0$.

Now, $G[a]=10 \cdot[1+a] \cdot[1-c]-\frac{10 \cdot[1+a+b(a)] \cdot\left[1-c \cdot e^{-b(a) d}\right]}{1+2 \cdot b(a)}$, and so $\frac{d G}{d a}=10 \cdot[1-c]$ $-\frac{10 \cdot\left[1-\mathrm{c} \cdot \mathrm{e}^{-\mathrm{b}(\mathrm{a}) \mathrm{d}]}\right.}{1+2 \cdot \mathrm{b}(\mathrm{a})},\left(\right.$ as $\left.\mathrm{Fb}_{\mathrm{b}}[\cdot]=0\right)$. It is sufficient, therefore, to show $\mathrm{G}[\mathrm{a}]=0$ implies $[1$ $-c] \cdot[1+2 \cdot b(a)]>\left[1-c \cdot e^{-b(a) d}\right]$. Now, $G[a]=0$ yields

$$
[1+a] \cdot[1-c] \cdot[1+2 \cdot b(a)]=[1+a+b(a)] \cdot\left[1-c \cdot e^{-b(a) d}\right]
$$

Further, as $b(a)>0$, it follows that $1+a+b(a)>1+a$, and so $\frac{d G[a]}{d a}>0$, as desired.

That is, starting at $\mathrm{a}=\infty$, as a falls we have $\mathrm{b}^{*}[\mathrm{a}, \mathrm{c}, \mathrm{d}]=0$, until we come to the critical value of a for which there are two optimal values for b. Further, such a critical value, if it exists, is unique, for we always move from $b=0$ to $b>0$ (as a falls). Hence, for $a$ below this critical value, $\mathrm{b}^{*}[\mathrm{a}, \mathrm{c}, \mathrm{d}]>0$ and $\frac{\partial \mathrm{b} *(\mathrm{a}, \mathrm{c}, \mathrm{d})}{\partial \mathrm{a}}<0$.

\section{ii) Proof of Proposition 2}


$F_{b c}[\cdot]=\left(\frac{10}{[1+2 \cdot b]^{2}}\right) \cdot\left\{d \cdot[1+a+b] \cdot[1+2 \cdot b] \cdot e^{-b d}+[1+2 \cdot a] \cdot e^{-b d}\right\}>0$. Hence, if $b(a)$ is given by $\mathrm{Fb}_{\mathrm{b}}[\cdot]=0$ and $\mathrm{Fbb}_{\mathrm{b}}[\cdot]<0$, then $\partial \mathrm{b}(\mathrm{a}) / \partial \mathrm{a}>0$. It is therefore sufficient to show that if $\mathrm{G}[\mathrm{c}]=\mathrm{F}[\mathrm{a}, 0, \mathrm{c}, \mathrm{d}]-\mathrm{F}[\mathrm{a}, \mathrm{b}(\mathrm{c}), \mathrm{c}, \mathrm{d}]=0$, and $\mathrm{b}(\mathrm{c})>0$, then $\frac{\partial \mathrm{G}[\mathrm{c}]}{\partial \mathrm{c}}<0$. Now, as $\mathrm{Fb}[\mathrm{a}, \mathrm{b}(\mathrm{c}), \mathrm{c}, \mathrm{d}]=0$,

$$
\frac{\partial \mathrm{G}[\mathrm{c}]}{\partial \mathrm{c}}=\frac{10 \cdot[1+\mathrm{a}+\mathrm{b}(\mathrm{c})] \cdot \mathrm{e}^{-\mathrm{b}(\mathrm{c}) \mathrm{d}}}{1+2 \cdot \mathrm{b}(\mathrm{c})}-10 \cdot[1+\mathrm{a}]
$$

Now, $G[c]=[c-1] \cdot\left[\frac{\partial G[c]}{\partial c}\right]+\frac{10 \cdot[1+a+b(c)] \cdot\left[e^{-b(c) d}-1\right]}{1+2 \cdot b(c)}=0$. Hence, for $b(c)>0$ and $\mathrm{d}>0$, it must be the case that $[\mathrm{c}-1] \cdot\left[\frac{\partial \mathrm{G}[\mathrm{c}]}{\partial \mathrm{c}}\right]>0 ; \frac{\partial \mathrm{G}[\mathrm{c}]}{\partial \mathrm{c}}<0$.

\section{iii) Proof of Proposition 3}

Part (i): Consider the point at which $\mathrm{c}=\frac{4-\mathrm{d}}{4+\mathrm{d}}$ intersects with $\mathrm{Fb}[\mathrm{a}, 0, \mathrm{c}, \mathrm{d}]=0$.

These two equalities yield $\mathrm{c}=\frac{1+2 \cdot \mathrm{a}}{1+2 \cdot \mathrm{a}+\mathrm{d} \cdot[1+\mathrm{a}]}=\frac{4-\mathrm{d}}{4+\mathrm{d}}$, and so $\mathrm{d}=\frac{2}{1+\mathrm{a}}$.

Now, consider the locus of points given by $F[a, 0, c, d]=F[a, b, c, d], F b[a, b, c, d]=0$.

Given a, this yields c as an implicit function of $d$, which intersects the curve, $c=\frac{4-d}{4+d}$ when $d=\frac{2}{1+a}$.

Now, it is our claim that for $c \in\left(c[d], \frac{4-d}{4+d}\right)$, some high values of a yield $F_{b}[b]=0$, for $b>0$, even though $b^{*}[\cdot]=0$. Where does this turning point come from? (i) It could 
always be there from $a=\infty$, or (ii) it could come from $b=0$, or (iii) from $b=\infty$, or finally, (iv) it may emerge from $\mathrm{a}<\infty$ and $0<\mathrm{b}<\infty$.

From Lemma $1, \mathrm{Fb}_{b}[0]=0$ implies $\mathrm{Fba}_{\mathrm{ba}}[0]<0$. This rules out (ii). Similarly, the observation that $\mathrm{Fb}_{b}[\mathrm{~b}]<0$ for $\mathrm{b}$ large enough rules out (iii). Hence, either (i) or (iv) would appear to be true.

Part (ii): Given $[\mathrm{a}, \mathrm{d}], \mathrm{c}^{\prime}$ is given by $\mathrm{Fb}\left[\mathrm{a}, 0, \mathrm{c}^{\prime}, \mathrm{d}\right]=0$;

$$
c^{\prime}=\frac{1+2 \cdot a}{1+2 \cdot a+d \cdot[1+a]}
$$

For $\mathrm{c}>\mathrm{c}^{\prime}, \mathrm{Fb}[\mathrm{a}, 0, \mathrm{c}, \mathrm{d}]>0$, and so $\mathrm{b}=0$ is the only local minimum. It is important to notice that a local minimum requires a local maximum, and so a local minimum (with $\mathrm{b}$ $>0$ ) must emerge from a situation when $\mathrm{Fb}_{\mathrm{b}}[\cdot]=\mathrm{Fbb}[\cdot]=0$. Now, $\mathrm{Fbb}[\cdot]=0$ requires 2 $=\mathrm{d} \cdot[1+\mathrm{a}+\mathrm{b}]$, or $\mathrm{b}=\frac{2-\mathrm{d}[1+\mathrm{a}]}{\mathrm{d}}$. Substituting this expression into $\mathrm{Fb}[\cdot]=0$ yields $\mathrm{c}^{\prime \prime}$ $=\frac{\mathrm{d} \cdot[1+2 \cdot a] \cdot \mathrm{e}^{2-d \cdot[1+a]}}{8-\mathrm{d} \cdot[1+2 \cdot a]}$. It is easily verified that if $\mathrm{d} \cdot[1+\mathrm{a}]<2$, then $\mathrm{c}^{\prime \prime}<1$. Further, it is also the case that $\mathrm{c}^{\prime}>\mathrm{c}^{\prime \prime}$.

To verify $\mathrm{c}^{\prime \prime}<1$ consider $8>\mathrm{g}[\mathrm{a}, \mathrm{d}]=\mathrm{d} \cdot[1+2 \cdot \mathrm{a}] \cdot\left\{1+\mathrm{e}^{2-\mathrm{d} \cdot[1+\mathrm{a}]}\right\}$ and $\frac{\partial \mathrm{g}}{\partial \mathrm{d}}=[1+2 \cdot \mathrm{a}] \cdot\left\{1+[1-\mathrm{d} \cdot(1+\mathrm{a})] \cdot \mathrm{e}^{2-\mathrm{d} \cdot[1+\mathrm{a}]}\right\}>0$, as $1+[\mathrm{x}-1] \cdot \mathrm{e}^{\mathrm{x}}>0, \forall \mathrm{x}>0$, where $x=2-d \cdot[1+a]>0$. Hence, for any $a, g[a, d]$ is maximized when $d \cdot[1+a]=2$, yielding $\mathrm{g}[\mathrm{a}, \mathrm{d}]=4+2 \cdot \mathrm{a} \cdot \mathrm{d}<8($ as $\mathrm{a} \cdot \mathrm{d}<2)$. 
To verify $c^{\prime}>c^{\prime \prime}$, simply notice that $\mathrm{F}_{b}[\mathrm{a}, 0, \mathrm{c}, \mathrm{d}]=0$ implies $\mathrm{Fbb}_{b}[\mathrm{a}, 0, \mathrm{c}, \mathrm{d}]<0$ (as d·[1 $+a]<2$ ), and so for $c>c^{\prime}$, there is no point $b$ such that $F b[a, b, c, d]=0$ and $F b b[a, b$, $\mathrm{c}, \mathrm{d}] \geq 0(\mathrm{Fbb}[\mathrm{a}, 0, \mathrm{c}, \mathrm{d}]>0$ implies a unique local maximum $)$. Hence it must be the case that $\mathrm{c}^{\prime}>\mathrm{c}^{\prime \prime}$.

\section{(iv) Proof of Proposition 4}

Assume, by contradiction, that there are two different local maxima

$\mathrm{b}_{1}$ and $\mathrm{b}_{2}$ contained in $(0, \infty)$. Without loss of generality we may assume that $\mathrm{b}_{1}<\mathrm{b}_{2}$. As a result there must exist $a b_{3} \in\left(b_{1}, b_{2}\right)$ at which EU attains a local minimum. Now on the one hand, according to the necessary and sufficient condition derived in Lemma 1 above, we must have

$$
a+b_{1} \geq(2-d) / d
$$

But because $b_{3}>b_{1}$ we must have

$$
a+b_{3} \geq(2-d) / d
$$

which implies that $b_{3}$ is a strict local maximum. A contradiction.

\section{v) Proof of Proposition 5}

First we establish Proposition 5': Given $b>0$ and $d>0$ satisfying the following conditions:

(i) $1+0.5 \mathrm{~d}(1+2 \mathrm{~b})-\mathrm{e}^{\text {bd }}<0.5 \mathrm{~d}$, and

(ii) $1+\mathrm{d}(1+\mathrm{b})(1+2 \mathrm{~b})-\mathrm{e}^{\mathrm{bd}} \geq \mathrm{d}(1+\mathrm{b})^{2}$, 
there exists $a^{*}=a(b, d) \geq 0$, and $c^{*}=c(b, d)$ such that

(a) $\mathrm{F}\left(\mathrm{a}^{*}, 0, \mathrm{c}^{*}, \mathrm{~d}\right)=\mathrm{F}\left(\mathrm{a}^{*}, \mathrm{~b}, \mathrm{c}^{*}, \mathrm{~d}\right)$, and

(b) $\mathrm{F}_{\mathrm{b}}\left(\mathrm{a}^{*}, \mathrm{~b}, \mathrm{c}^{*}, \mathrm{~d}\right)$,

If, in addition (iii) $\mathrm{a} *+\mathrm{b}>\frac{2-\mathrm{d}}{\mathrm{d}}$ then

(c) $\{0, \mathrm{~b}\}$ are the only maxima of $\mathrm{F}\left(\mathrm{a}^{*}, ., \mathrm{c}^{*}, \mathrm{~d}\right)$, and

(d) Given the above $\mathrm{c}^{*}$ and $\mathrm{d}$, as a increases from zero to a* the optimal offer remains unique and decreases to $\mathrm{b}$ at $\mathrm{a}=\mathrm{a} *$ where it has two values $\{0, \mathrm{~b}\}$. As $\mathrm{a}$ increases above $\mathrm{a}=\mathrm{a}^{*}$ the optimal offer remains uniquely 0 .

Let

$$
c=c(a, b, d)=\frac{(1+2 a) e^{b d}}{1+2 a+d(1+a+b)(1+2 b)}
$$

and

$$
G(a)=10(1+a)[1-c(a, b, d)]-\frac{10(1+a+b)\left(1-c(a, b, d) e^{-b d}\right)}{(1+2 b)}
$$

It is easy to verify that (i) of the proposition implies that $\mathrm{G}(\infty)<0$; and that (ii) implies that $\mathrm{G}(0) \geq 0$. Hence, there exists $\mathrm{a}^{*} \geq 0$ such that $\mathrm{G}\left(\mathrm{a}^{*}\right)=0$, which is equivalent to part (a) of the proposition if we write $c\left(a^{*}, b, d\right)=c^{*}=c^{*}(b, d)$. Part (b) follows directly from the definition of $c(a, b, d)$. 
Now, if (iii) is satisfied, then $b$ is a local maximum of $F\left(a^{*}, ., c^{*}, d\right)$. Part (c) follows from the Corollary. Conclusion (d) follows from arguments that establish the previous propositions.

Now let $b_{1}=b_{1}(d)$ be the implicit function solved from $1+0.5 d(1+2 b)-e^{b d}=0.5 d$ and $b_{2}=b_{2}(d)$ be the implicit function solved from $1+d(1+b)(1+2 b)-e^{b d}=d(1+b)^{2}$. It is the case that $b_{1}(d)<b_{2}(d)$. In addition, let $c_{1}(d)=c^{*}\left[b_{1}(d), d\right]$, and $c_{2}(d)=c^{*}\left[b_{2}(d), d\right]$, then $c_{1}(d)>c_{2}(d)$ for any $b>\frac{2-d}{d}$. These statements mean that Proposition 5' can be expressed as

Proposition 5: Given any $\mathrm{d}<2$ and $\mathrm{c} \in\left(\mathrm{c}_{2}(\mathrm{~d}), \mathrm{c}_{1}(\mathrm{~d})\right)$ there exists an $\mathrm{a}^{*}=\mathrm{a}^{*}(\mathrm{c}, \mathrm{d})$, such that $\mathrm{F}\left(\mathrm{a}^{*}, ., \mathrm{c}, \mathrm{d}\right)$ has precisely two global maxima $\{0, \mathrm{~b}>0\}$.

\section{iv) Proof of Proposition 6.}

The first-order condition yields:

$$
F_{b}[a, b, c, d, q]=c \cdot d \cdot U[g(a, b), q] \cdot e^{-b d}+g b(a, b) \cdot U_{1}[g(a, b), q] \cdot\left[1-c \cdot e^{-b d}\right] .
$$

Now, $\mathrm{Fb}_{b}[\mathrm{a}, 0, \mathrm{c}, \mathrm{d}, \mathrm{q}]=\mathrm{c} \cdot \mathrm{d} \cdot \mathrm{U}[10 \cdot(1+\mathrm{a}), \mathrm{q}]-10 \cdot(1+2 \cdot \mathrm{a}) \cdot(1-\mathrm{c}) \cdot \mathrm{U}_{1}[10 \cdot(1+\mathrm{a}), \mathrm{q}]$, which will be positive for c close enough to 1 (given $\mathrm{a}, \mathrm{d}$, and $\mathrm{q}$ ), while for $\mathrm{b}$ large enough, $\mathrm{Fb}[\mathrm{a}, \mathrm{b}, \mathrm{c}, \mathrm{d}, \mathrm{q}]<0$ (as $\mathrm{b}^{\mathrm{n}} \cdot \mathrm{e}^{-\mathrm{bd}} \rightarrow 0$ as $\mathrm{b} \rightarrow \infty$, for $\mathrm{n}$ positive and finite). Hence, if it can be shown that $F_{b}[a, b, c, d, q]=0$ implies $F b b[a, b, c, d, q]<0$, then there exists a unique optimal value of $b ; b^{*}[a, c, d, q]$. Notice, if $F b[a, 0, c, d q] \geq 0$, the first-order condition yields $\mathrm{b}^{*}[\cdot]$, while $\mathrm{Fb}[\mathrm{a}, 0, \mathrm{c}, \mathrm{d}, \mathrm{q}]<0$ implies $\mathrm{b}^{*}[\cdot]=0$. 
Lemma 2: If $\mathrm{c}>\frac{4-\mathrm{d}}{4+\mathrm{d}}$, then $\mathrm{Fb}[\mathrm{a}, \mathrm{b}, \mathrm{c}, \mathrm{d}, \mathrm{q}]=0$ implies $\mathrm{Fbb}[\mathrm{a}, \mathrm{b}, \mathrm{c}, \mathrm{d}, \mathrm{q}]<0$.

Hence, a unique optimal value of $b>0$ - written $b^{*}[a, c, d, q]$ - exists.

Proof of Lemma 2: given (a, c, d, q), suppose $\exists b^{*}$ such that $F b[a, b *, c, d, q]=0$. Now,

$$
\begin{aligned}
F_{b b}\left[a, b^{*}, c, d, q\right]= & {\left[g b\left(a, b^{*}\right)\right]^{2 \cdot} U_{11}\left[g\left(a, b^{*}\right), q\right] \cdot\left[1-c \cdot e^{-b^{*} d}\right] } \\
& +U_{1}\left[g\left(a, b^{*}\right), q\right] \cdot\left\{d \cdot g b\left(a, b^{*}\right) \cdot\left[1+c \cdot e^{-b^{*} d}\right]\right. \\
& \left.+g b b\left(a, b^{*}\right) \cdot\left[1-c \cdot e^{-b^{*} d}\right]\right\}<0
\end{aligned}
$$

if $d \cdot g b\left(a, b^{*}\right) \cdot\left[1+c \cdot e^{-b^{*} d}\right]+g b b\left(a, b^{*}\right) \cdot\left[1-c \cdot e^{-b * d}\right]<0\left(\right.$ as $\left.U_{1}[\cdot]>0\right)$.

Notice, this condition is sufficient but not necessary, as it ignores the first term, [gb(a, $\left.\left.\mathrm{b}^{*}\right)\right]^{2 \cdot} \cdot \mathrm{U}_{11}\left[\mathrm{~g}\left(\mathrm{a}, \mathrm{b}^{*}\right), \mathrm{q}\right] \cdot\left[1-\mathrm{c} \cdot \mathrm{e}^{-\mathrm{b}^{*} \mathrm{~d}}\right]$, which is clearly negative (if $\mathrm{U}_{11}[\cdot]=0$, then the condition also becomes necessary). Now,

$$
\begin{aligned}
& d \cdot g b\left(a, b^{*}\right) \cdot\left[1+c \cdot e^{-b^{*} d}\right]+g b b\left(a, b^{*}\right) \cdot\left[1-c \cdot e^{-b^{*} d}\right] \\
&=10 \cdot[1+2 \cdot a] \cdot\left[1+2 \cdot b^{*}\right]^{-3} \cdot\left\{4 \cdot\left[1-c \cdot e^{-b^{*} d}\right]\right. \\
&\left.-d \cdot\left[1+2 \cdot b^{*}\right] \cdot\left[1+c \cdot e^{-b^{*} d}\right]\right\}<0
\end{aligned}
$$

iff

$$
4<4 \cdot c \cdot e^{-b * d}+d \cdot\left[1+2 \cdot b^{*}\right] \cdot\left[1+c \cdot e^{-b * d}\right]
$$




$$
=d \cdot\left(1+2 \cdot b^{*}\right)+c \cdot\left[4+d \cdot\left(1+2 \cdot b^{*}\right)\right] \cdot e^{-b * d}
$$

Treating the RHS as a function of $\mathrm{b}^{*}$, the second-derivative is strictly positive $\forall \mathrm{b}^{*}$, while the first-derivative is positive for $b^{*}$ large enough. Two possibilities therefore emerge; either (i) the derivative at $b^{*}=0$ is negative - in which case the RHS of (A1) is minimized when $b^{*}=b^{\prime}>0$, and $2=c \cdot\left[2+d \cdot\left(1+2 \cdot b^{\prime}\right)\right] \cdot e^{-b^{\prime} d}$; or (ii) the derivative at $\mathrm{b}^{*}=0$ is non-negative - in which case the RHS of (A1) is minimized when $b^{*}=0$.

(i) If $\mathrm{c} \cdot(2+\mathrm{d})>2$, then $\exists \mathrm{b}^{\prime}>0$ such that $2=\mathrm{c} \cdot\left[2+\mathrm{d} \cdot\left(1+2 \cdot \mathrm{b}^{\prime}\right)\right] \cdot \mathrm{e}^{-\mathrm{b}^{\prime} \mathrm{d}}$, and so the RHS of (A1) becomes $d \cdot\left(1+2 \cdot b^{\prime}\right)+2 \cdot\left[4+d \cdot\left(1+2 \cdot b^{\prime}\right)\right] \cdot\left[2+d \cdot\left(1+2 \cdot b^{\prime}\right)\right]^{-1}=d \cdot(1+$ $\left.2 \cdot b^{\prime}\right)+2+4 \cdot\left[2+d \cdot\left(1+2 \cdot b^{\prime}\right)\right]^{-1}>4$ if, and only if, $4>\left[2+d \cdot\left(1+2 \cdot b^{\prime}\right)\right] \cdot\left[2-d \cdot\left(1+2 \cdot b^{\prime}\right)\right]$ $=4-\left[d \cdot\left(1+2 \cdot b^{\prime}\right)\right]^{2}$, which is always true. Hence, $\mathrm{Fbb}\left[a, b^{*}, c, d, q\right]<0$.

(ii) If $c \cdot(2+d) \leq 2$, the RHS of (A1) is minimized when $b^{\prime}=0$ - as the RHS of (A1) is an increasing function of $\mathrm{b}, \forall \mathrm{b}>0$. When $\mathrm{b}=0$, (A1) becomes $4<\mathrm{d}+\mathrm{c} \cdot(4+$ d), which is true if, and only if, $d>\frac{4 \cdot[1-c]}{1+c}$.

Notice, $\frac{2 \cdot[1-\mathrm{c}]}{\mathrm{c}}>\frac{4 \cdot[1-\mathrm{c}]}{1+\mathrm{c}}, \forall \mathrm{c} \in(0,1)$, and so if $\mathrm{d}>\frac{4 \cdot[1-\mathrm{c}]}{1+\mathrm{c}}$, then $\mathrm{Fb}\left[\mathrm{a}, \mathrm{b}^{*}, \mathrm{c}, \mathrm{d}, \mathrm{q}\right]$ $=0$ implies $\mathrm{Fbb}_{\mathrm{b}}\left[\mathrm{a}, \mathrm{b}^{*}, \mathrm{c}, \mathrm{d}, \mathrm{q}\right]<0$.

Proof of Proposition 6: it uses Lemma 2 and

$$
\mathrm{g}_{\mathrm{a}}(\mathrm{a}, \mathrm{b})=\frac{20}{1+2 \cdot \mathrm{b}}, \quad \mathrm{gb}(\mathrm{a}, \mathrm{b})=\frac{-10 \cdot[1+2 \cdot \mathrm{a}]}{[1+2 \cdot \mathrm{b}]^{2}}, \mathrm{~g}_{\mathrm{aa}}(\mathrm{a}, \mathrm{b})=0
$$




$$
g_{a b}(a, b)=g b a(a, b)=\frac{-20}{[1+2 \cdot b]^{2}} \text {, and } g b b(a, b)=\frac{40 \cdot[1+2 \cdot a]}{[1+2 \cdot b]^{3}}
$$

Turning to the proof, either (i) $\mathrm{Fb}_{\mathrm{b}}[\mathrm{a}, 0, \mathrm{c}, \mathrm{d}, \mathrm{q}]<0$ - yielding $\mathrm{b}^{*}[\mathrm{a}, \mathrm{c}, \mathrm{d}, \mathrm{q}]=0-$ or (ii) $F_{b}[a, 0, c, d, q] \geq 0$ - and so $b^{*}[a, c, d, q]$ is given by $F b\left[a, b^{*}, c, d, q\right]=0$.

(i) $\mathrm{As}_{\mathrm{bb}}[\cdot]$ is $\mathrm{C}^{1}$, if $\mathrm{F}_{b}[\mathrm{a}, 0, \mathrm{c}, \mathrm{d}, \mathrm{q}]<0$, this inequality will be maintained for an open neighborhood of [a, c, d, q]. Hence, $b^{*}\left[a^{\prime}, c^{\prime}, d^{\prime}, q^{\prime}\right]=0, \forall\left[a^{\prime}, c^{\prime}, d^{\prime}, q^{\prime}\right]$ in the neighborhood. It is therefore trivially established that $b^{*}[\cdot]$ is non-increasing in a and $q$, and non-decreasing in $\mathrm{c}$ (and d).

(ii) From Lemma $2 \mathrm{Fb}_{b}[\mathrm{a}, 0, \mathrm{c}, \mathrm{d}, \mathrm{q}]=0$ ensures $\mathrm{Fbb}_{\mathrm{b}}\left[\mathrm{a}, \mathrm{b}^{*}, \mathrm{c}, \mathrm{d}, \mathrm{q}\right]<0$, and hence it is sufficient to show $\mathrm{Fba}_{b a}\left[\mathrm{a}, \mathrm{b}^{*}, \mathrm{c}, \mathrm{d}, \mathrm{q}\right]<0, \mathrm{Fbq}_{\mathrm{bq}}\left[\mathrm{a}, \mathrm{b}^{*}, \mathrm{c}, \mathrm{d}, \mathrm{q}\right]<0$, and $\mathrm{Fbc}_{b c}[\mathrm{a}$, $\left.b^{*}, c, d, q\right]>0$.

$$
\begin{aligned}
\mathrm{F}_{b a}\left[a, b^{*}, c, d, q\right]=c \cdot d \cdot g_{a}\left(a, b^{*}\right) \cdot U_{1}\left[g\left(a, b^{*}\right), q\right] \cdot e^{-b^{*} d} \\
+\left[1-c \cdot e^{-b^{*} d}\right] \cdot\left\{g_{a}\left(a, b^{*}\right) \cdot g b\left(a, b^{*}\right) \cdot U_{11}[g(a, b), q]\right. \\
\left.+g_{b a}\left(a, b^{*}\right) \cdot U_{1}[g(a, b), q]\right\}<0
\end{aligned}
$$

iff

$$
\begin{aligned}
& \mathrm{U}\left[\mathrm{g}\left(\mathrm{a}, \mathrm{b}^{*}\right), \mathrm{q}\right] \cdot\left\{\mathrm{gb}\left(\mathrm{a}, \mathrm{b}^{*}\right) \cdot \mathrm{U}_{1}\left[\mathrm{~g}\left(\mathrm{a}, \mathrm{b}^{*}\right), \mathrm{q}\right]\right\}^{-1} \cdot\left\{\mathrm{g}_{\mathrm{a}}\left(\mathrm{a}, \mathrm{b}^{*}\right) \cdot \mathrm{gb}\left(\mathrm{a}, \mathrm{b}^{*}\right) \cdot \mathrm{U}_{11}\left[\mathrm{~g}\left(\mathrm{a}, \mathrm{b}^{*}\right), \mathrm{q}\right]\right. \\
& \left.+g_{b a}\left(a, b^{*}\right) \cdot U_{1}\left[g\left(a, b^{*}\right), q\right]\right\}-g_{a}\left(a, b^{*}\right) \cdot U_{1}\left[g\left(a, b^{*}\right), q\right]>0
\end{aligned}
$$

iff, 


$$
\begin{array}{r}
g_{a}\left(a, b^{*}\right) \cdot g b\left(a, b^{*}\right) \cdot\left\{U_{1}\left[g\left(a, b^{*}\right), q\right]^{2}-U_{11}\left[g\left(a, b^{*}\right), q\right] \cdot U\left[g\left(a, b^{*}\right), q\right]\right\}> \\
\quad g b a\left(a, b^{*}\right) \cdot U_{1}\left[g\left(a, b^{*}\right), q\right] \cdot U\left[g\left(a, b^{*}\right), q\right]
\end{array}
$$

iff,

$$
\begin{gathered}
g_{a}\left(a, b^{*}\right) \cdot g b\left(a, b^{*}\right) \cdot g b a\left(a, b^{*}\right)^{-1} \cdot\left\{U_{1}\left[g\left(a, b^{*}\right), q\right]^{2}-U_{11}\left[g\left(a, b^{*}\right), q\right] \cdot U\left[g\left(a, b^{*}\right), q\right]\right\} \\
<U_{1}\left[g\left(a, b^{*}\right), q\right] \cdot U\left[g\left(a, b^{*}\right), q\right]
\end{gathered}
$$

Finally, $g_{a}\left(a, b^{*}\right) \cdot g b\left(a, b^{*}\right) \cdot g b a\left(a, b^{*}\right)^{-1}=g\left(a, b^{*}\right)-5$, and so Assumption 4(iii) ensures $\mathrm{F}_{\mathrm{ba}}\left[\mathrm{a}, \mathrm{b}^{*}, \mathrm{c}, \mathrm{d}, \mathrm{q}\right]<0$.

Now, if $F_{b}\left[a, b^{*}, c, d, q\right]=0$, then

$$
[c \cdot d]^{-1} \cdot g b\left(a, b^{*}\right) \cdot\left[1-c \cdot e^{-b^{*} d}\right] \cdot e b^{*} d=-U\left[g\left(a, b^{*}\right), q\right] \cdot U_{1}\left[g\left(a, b^{*}\right), q\right]^{-1}
$$

This ensures

$$
\begin{gathered}
F_{b q}\left[a, b^{*}, c, d, q\right]=c \cdot d \cdot U_{2}\left[g\left(a, b^{*}\right), q\right] \cdot e^{-b^{*} d}+g b\left(a, b^{*}\right) \cdot U_{12}\left[g\left(a, b^{*}\right), q\right] \cdot[1 \\
\left.-c \cdot e^{-b^{*} d}\right]<0
\end{gathered}
$$

iff

$$
\mathrm{U}_{1}\left[\mathrm{~g}\left(\mathrm{a}, \mathrm{b}^{*}\right), \mathrm{q}\right] \cdot \mathrm{U}_{2}\left[\mathrm{~g}\left(\mathrm{a}, \mathrm{b}^{*}\right), \mathrm{q}\right]-\mathrm{U}_{12}\left[\mathrm{~g}\left(\mathrm{a}, \mathrm{b}^{*}\right), \mathrm{q}\right] \cdot \mathrm{U}\left[\mathrm{g}\left(\mathrm{a}, \mathrm{b}^{*}\right), \mathrm{q}\right]<0,
$$

which is guaranteed from Assumption 4(iv). Finally

$$
\begin{aligned}
F_{b c}\left[a, b^{*}, c, d, q\right] & =d \cdot U\left[g\left(a, b^{*}\right), q\right] \cdot e^{-b^{*} d}-g b\left(a, b^{*}\right) \cdot U_{1}\left[g\left(a, b^{*}\right), q\right] \cdot e^{-b^{*} d} \\
& =c^{-1} \cdot F b\left[a, b^{*}, c, d, q\right]-c^{-1} \cdot g b\left(a, b^{*}\right) \cdot U_{1}\left[g\left(a, b^{*}\right), q\right]>0 .
\end{aligned}
$$




\section{Appendix 2: Information and the Ultimatum Game Under Risk Neutrality}

First, let us generalize the ultimatum game by letting the size of the pie be A. In the world of complete information and risk neutrality, if player 1 offers

$$
y \geq A \cdot b \cdot[1+2 \cdot b]^{-1}
$$

Player 2 (with parameter, b) will accept, while $\mathrm{y}<\mathrm{A} \cdot \mathrm{b} \cdot[1+2 \cdot \mathrm{b}]^{-1}$ will result in rejection. Hence, Player 1 chooses b so as to maximize their expected utility:

$$
\mathrm{EU}^{1}=\{\mathrm{x}+\mathrm{a} \cdot[\mathrm{x}-\mathrm{y}]\} \cdot\left[1-\mathrm{c} \cdot \mathrm{e}^{-\mathrm{db}}\right]=\mathrm{A} \cdot[1+\mathrm{a}+\mathrm{b}] \cdot[1+2 \mathrm{~b}]^{-1} \cdot\left[1-\mathrm{c} \cdot \mathrm{e}^{-\mathrm{db}}\right]
$$

\section{An unknown value for $A$.}

Treat $\mathrm{A}$ as a random variable, $\mathrm{p}[\mathrm{A}]=$ prob $\mathrm{A}, \mathrm{A}^{*}=\sum_{\mathrm{A}} \mathrm{p}[\mathrm{A}] \cdot \mathrm{A}, \mathrm{x}(\mathrm{A})=\mathrm{A}-\mathrm{y}$, and so

$$
\mathrm{U}^{2}[\mathrm{~A}]=\mathrm{y}+\mathrm{b} \cdot[2 \cdot \mathrm{y}-\mathrm{A}]=[1+2 \cdot \mathrm{b}] \cdot \mathrm{y}-\mathrm{b} \cdot \mathrm{A}
$$

\section{Common information.}

Both players know the distribution of A, but no-one knows the realized value (until the game is over). The offer made by Player 1 therefore reveals nothing about the size of $\mathrm{A}$, and both players know this.

$$
\begin{gathered}
\mathrm{EU}^{2}=\sum_{\mathrm{A}} \mathrm{p}[\mathrm{A}] \cdot\{[1+2 \cdot \mathrm{b}] \cdot \mathrm{y}-\mathrm{b} \cdot \mathrm{A}\}= \\
=[1+2 \cdot \mathrm{b}] \cdot \mathrm{y}-\mathrm{b} \cdot \sum_{\mathrm{A}} \mathrm{p}[\mathrm{A}] \cdot \mathrm{A} \\
=[1+2 \cdot \mathrm{b}] \cdot \mathrm{y}-\mathrm{b} \cdot \mathrm{A}^{*}
\end{gathered}
$$

Given $y=A * \cdot b \cdot[1+2 \cdot b]^{-1}$, then $x[A]=A-A * \cdot b \cdot[1+2 \cdot b]^{-1}$,

$$
x[A]-y=A-2 \cdot A * b \cdot[1+2 \cdot b]^{-1},
$$




$$
\begin{aligned}
& \mathrm{U}^{1}[\mathrm{~A}]=\mathrm{x}[\mathrm{A}]+\mathrm{a} \cdot[\mathrm{x}(\mathrm{A})-\mathrm{y}]=\mathrm{A} \cdot[1+\mathrm{a}]-\mathrm{A}^{*} \cdot \mathrm{b} \cdot[1+2 \cdot \mathrm{a}] \cdot[1+2 \cdot \mathrm{b}]^{-1} \\
& \begin{aligned}
\sum_{\mathrm{A}} \mathrm{p}[\mathrm{A}] \cdot \mathrm{U}^{1}[\mathrm{~A}] & =\sum_{\mathrm{A}} \mathrm{p}[\mathrm{A}] \cdot \mathrm{A} \cdot[1+\mathrm{a}]-\mathrm{A}^{*} \cdot \mathrm{b} \cdot[1+2 \cdot \mathrm{a}] \cdot[1+2 \cdot \mathrm{b}]^{-1} \\
& =\mathrm{A}^{*} \cdot[1+\mathrm{a}]-\mathrm{A}^{*} \cdot \mathrm{b} \cdot[1+2 \cdot \mathrm{a}] \cdot[1+2 \cdot \mathrm{b}]^{-1} \\
& =\mathrm{A}^{*} \cdot[1+\mathrm{a}+\mathrm{b}] \cdot[1+2 \cdot \mathrm{b}]^{-1} .
\end{aligned}
\end{aligned}
$$

This is the simplest case, where the choice of $\mathrm{y}$ is consistent with the support of A. Put another way, Player 1 is restricted to $\mathrm{y}^{-} \mathrm{A}^{-}$(the minimum value of $\mathrm{A}$ in the support).

\section{Private Information but no updating.}

Consider now the case where Player 1 is told $A$, but must still choose $y \leq A^{-}$. Further, Player 2 does not use 1's offer to update her beliefs about A.

Player 1 seeks to maximize

$$
\begin{aligned}
& \mathrm{F}=\left\{\mathrm{A} \cdot[1+\mathrm{a}]-\mathrm{A}^{*} \cdot \mathrm{b} \cdot[1+2 \cdot a] \cdot[1+2 \cdot \mathrm{b}]^{-1}\right\} \cdot\left[1-\mathrm{c} \cdot \mathrm{e}^{-\mathrm{db}}\right] \\
& \begin{aligned}
\mathrm{D}_{\mathrm{b}} \mathrm{F}=\mathrm{A} \cdot[1+\mathrm{a}] \cdot \mathrm{c} \cdot \mathrm{d} \cdot \mathrm{e}^{-\mathrm{db}} & \\
& -\mathrm{A}^{*} \cdot[1+2 \cdot a] \cdot[1+2 \cdot b]^{-2} \cdot\left\{1-[1-(1+2 \cdot b) \cdot b \cdot d] \cdot c \cdot e^{-d b^{*}}\right\}
\end{aligned}
\end{aligned}
$$

Further, given $\mathrm{a}, \mathrm{A}$, and $\mathrm{y}>0$, if $\mathrm{A}^{*}$ is lowered, then $\mathrm{y}$ will fall and $\mathrm{y} \cdot\left[\mathrm{A}^{*}\right]^{-1}$ will rise. Notice, this result is consistent with Croson (1996). In that paper $A^{*}=A=10$ yields $y$ $=4.5$ and $\mathrm{y} \cdot\left[\mathrm{A}^{*}\right]^{-1}=45 \%$ (on average), while $\mathrm{A}^{*}=7.46$ yields $\mathrm{y}=3.57$ and $\mathrm{y} \cdot\left[\mathrm{A}^{*}\right]^{-1}=$ $48 \%$. 
Notice, this section assumes all Players have the same prior $\left(\mathrm{A}^{*}\right)$, which is clearly not the case in Croson's (1996) experiment; there is a distribution of priors for respondents, and proposers must form a belief about these priors.

\section{Private Information with the choice of revelation.}

Player 1 observes A. She has the option to reveal this value to Player 2 (when she announces y). Notice, she does not announce a size of the pie, $\mathrm{A}^{\wedge}$, for this announcement could be a lie. Rather she presses a button that reveals the true value of A. Player 1 must therefore choose between telling the truth and remaining silent.

Now, from game II, if Player 1 observes $\mathrm{A}<\mathrm{A}^{*}$, then she can increase the probability that 2 will accept a given offer, y, by revealing A. That is, Player 2 replaces A* with A and this will lower the critical value of $b$ associated with 2 accepting the offer, $y$.

Hence, if $\mathrm{A}<\mathrm{A}^{*}$, Player 1 reveals $\mathrm{A}$ (no matter what her offer, $\mathrm{y}$, is), while if $\mathrm{A} \geq \mathrm{A}^{*}$, Player 1 remains silent.

But now, Player 2 knows that silence implies $A \geq A^{*}$; silence generates a conditional probability distribution over A, with mean greater than $A^{*}$. If Player 1 observes a value of A less than this conditional mean, she will choose to reveal.

This process continues until we reach the point where Player 1 reveals, except when A is at its maximum value (silence means $\mathrm{A}$ is at its maximum, and so it is equivalent to Player 1 always revealing). We are now back in the game where the size of the pie, A, is common knowledge. Notice, the key assumption required to generate this result was that Player 1 had access to a revelation technology - rather than an announcement technology. 
IV Private Information with updating.

Player 1 announces y. Now, there are two pieces of private information that influence the offer; $\mathrm{a}$ and A. Player 2 is therefore able to form a conditional probability for A, as a function of $y$.

Let us consider the simplest case, where attention is restricted to two values for $\mathrm{A}, \mathrm{A}^{1}$ and $\mathrm{A}^{2}$, and two possible values for $\mathrm{y} ; 0$ and $\mathrm{y}^{*}$. Restricting the strategy set to this extent facilitates a sharp focus on updating by Player 2 . The probability of $A^{1}$ occurring is $\mathrm{p}$.

Let $\mathrm{p}[\mathrm{y}]$ be the probability of $\mathrm{A}^{1}$ being true, given $\mathrm{y}$. If $\mathrm{y}=0$, let

$$
\mathrm{A}[0]=\mathrm{p}[0] \cdot \mathrm{A}^{1}+[1-\mathrm{p}(0)] \cdot \mathrm{A}^{2}
$$

Similarly, $A\left[y^{*}\right]=p\left[y^{*}\right] \cdot A^{1}+\left[1-p\left(y^{*}\right)\right] \cdot A^{2}$.

If $\mathrm{y}=0$, then Player 2 accepts if $\mathrm{b}=0$, and rejects otherwise. Player 1 receives

$$
[1+\mathrm{a}] \cdot \mathrm{A} \cdot[1-\mathrm{c}]
$$

If $\mathrm{y}=\mathrm{y}^{*}$, Player 2 will accept if $\mathrm{b} \leq \mathrm{y}^{*} \cdot\left\{\mathrm{A}\left[\mathrm{y}^{*}\right]-2 \cdot \mathrm{y}^{*}\right\}^{-1}$, and so Player 1 receives

$$
\left\{[1+\mathrm{a}] \cdot \mathrm{A}-[1+2 \cdot \mathrm{a}] \cdot \mathrm{y}^{*}\right\} \cdot \mathrm{H}\left\{\mathrm{y}^{*} \cdot\left[\mathrm{A}\left(\mathrm{y}^{*}\right)-2 \cdot \mathrm{y}^{*}\right]^{-1}\right\}
$$

We then have $\mathrm{a}^{1}=\mathrm{a}\left[\mathrm{A}^{1}, \mathrm{~A}\left(\mathrm{y}^{*}\right)\right]$, and $\mathrm{a}^{2}=\mathrm{a}\left[\mathrm{A}^{2}, \mathrm{~A}\left(\mathrm{y}^{*}\right)\right]$. If Player 1 observes $\mathrm{A}^{1}$, then $\mathrm{y}^{*}$ will be offered iff $a<a^{1}$. If, however, Player 1 observes $A^{2}$, then $y^{*}$ will be offered iff a $<\mathrm{a}^{2}$

The probability of $\mathrm{y}^{*}$ being announced is: 


$$
\mathrm{p} \cdot \mathrm{H}\left[\mathrm{a}^{1}\right]+[1-\mathrm{p}] \cdot \mathrm{H}\left[\mathrm{a}^{2}\right]
$$

Hence:

$$
\mathrm{p}\left[\mathrm{y}^{*}\right]=\mathrm{p} \cdot \mathrm{H}\left[\mathrm{a}^{1}\right] \cdot\left\{\mathrm{p} \cdot \mathrm{H}\left[\mathrm{a}^{1}\right]+[1-\mathrm{p}] \cdot \mathrm{H}\left[\mathrm{a}^{2}\right]\right\}^{-1}
$$

This yields the equilibrium conditions for $\left[\mathrm{a}^{1}, \mathrm{a}^{2}, \mathrm{~A}\left(\mathrm{y}^{*}\right), \mathrm{p}\left(\mathrm{y}^{*}\right)\right]$ :

$$
\begin{aligned}
& A\left[y^{*}\right]=p\left[y^{*}\right] \cdot A^{1}+\left[1-p\left(y^{*}\right)\right] \cdot A^{2} \\
& {\left[1+a^{1}\right] \cdot A^{1} \cdot[1-c]=\left\{\left[1+a^{1}\right] \cdot A^{1}-\left[1+2 \cdot a^{1}\right] \cdot y^{*}\right\} \cdot\left\{1-c \cdot e^{-d y^{*} /\left[A\left(y^{*}\right)-2 \cdot y^{*}\right]}\right\}} \\
& {\left[1+a^{2}\right] \cdot A^{2} \cdot[1-c]=\left\{\left[1+a^{2}\right] \cdot A^{2}-\left[1+2 \cdot a^{2}\right] \cdot y^{*}\right\} \cdot\left\{1-c \cdot e^{-d y^{*} /\left[A\left(y^{*}\right)-2 \cdot y^{*}\right]}\right\}} \\
& p\left[y^{*}\right]=p \cdot H\left[a^{1}\right] \cdot\left\{p \cdot H\left[a^{1}\right]+[1-p] \cdot H\left[a^{2}\right]\right\}^{-1} .
\end{aligned}
$$

An example $\mathrm{c}=0.59, \mathrm{~d}=0.5, \mathrm{~A}^{1}=10, \mathrm{~A}^{2}=12, \mathrm{p}=0.9\left(\mathrm{~A}^{*}=10.2\right)$. Consider a situation in which $\mathrm{y}^{*}=4.7$. Two equilibria emerge.

First, $\mathrm{a}^{1}=0.285358, \mathrm{a}^{2}=0.874091, \mathrm{p}\left[\mathrm{y}^{*}\right]=0.87659, \mathrm{~A}\left[\mathrm{y}^{*}\right]=10.2468$. The probability that Player 1 announces $\mathrm{y}=0$ is $\mathrm{p}[0]=0.498505$, while the population proportion that accepts 1's offer is 0.687436 (notice, this is the unconditional acceptance; the conditional acceptance for $\mathrm{y}=0$ is $[1-\mathrm{c}])$.

Second, $\mathrm{a}^{1}=0, \mathrm{a}^{2}=0.216105, \mathrm{p}\left[\mathrm{y}^{*}\right]=0, \mathrm{~A}\left[\mathrm{y}^{*}\right]=12$. When Player 1 observes $\mathrm{A}^{1}$, she always offers $y=0$. This behavior is common knowledge, and so when Player 2 observes $y=y^{*}$, she knows Player 1 has observed $A^{2}$. Further $p[0]=0.952957$, while the population proportion that accepts 1 's offer is 0.426514 . Finally, given $p\left[y^{*}\right]$ and $\mathrm{A}\left[\mathrm{y}^{*}\right]$, consistency requires that when Player 1 observes $\mathrm{A}^{1}$, she prefers to offer $\mathrm{y}=0$, rather than $y=y^{*}$ (irrespective of her utility coefficient, a). Notice, the intuition here is 
that if Player 2 receives an offer of $y=y^{*}$, she infers that $A=A^{2}$, and so there is a high probability she will reject the offer. This discourages Player 1 from offering $y=y^{*}$.

The set of examples of multiple equilibria is likely to reduce as the strategy set is enlarged.

V Private Information with updating: a mean preserving spread.

Here we focus on the first type of equilibrium discussed above; where $A\left[y^{*}\right]<A^{2}$. The implications of increasing the variance of A (with the mean constant) are ambiguous.

[1] If $\mathrm{A}^{1}$ and $\mathrm{A}^{*}$ are fixed (with $\mathrm{p}$ and $\mathrm{A}^{2}$ adjusting to change the variance and preserve the mean), an increase in $\mathrm{p}$ causes $\mathrm{A}^{2}$ to rise and Var to also rise. The prob that Player 1 offers 0 rises, while 2's acceptance - of 0 - remains fixed at [1 - c].

This would seem to be consistent with the claim; the greater the uncertainty, the smaller the offer.

In the examples we have considered, with $\mathrm{p}$ and $\mathrm{A}^{2}$ rising, we observe $\mathrm{A}[\mathrm{y}]$ rising, $\mathrm{a}^{1}$ falling (when 1 observes $A^{1}$, the prob of her offering zero rises), $a^{2}$ rises (as $A^{2}$ is rising, the prob of 1 offering zero is falling), while the overall prob that Player 1 offers zero is rising.

[2] If $p$ and $A^{1}$ adjust, then a reduction in $p$ (and a decrease in $A^{1}$ ), causes the variance to rise. The prob that Player 1 offers 0 now falls.

In the examples, as $\mathrm{p}$ and $\mathrm{A}^{1}$ both fall, we observe $\mathrm{A}[\mathrm{y}]$ rising, $\mathrm{a}^{1}$ and $\mathrm{a}^{2}$ falling (the prob of offering zero rises, whether Player observes $\mathrm{A}^{1}$ or $\mathrm{A}^{2}$ ). However, the overall prob that Player 1 offers zero is falling. This paradoxical result is due to the direct 
impact of $p$ falling. As $p$ falls there is a switch from the "high prob of zero" pie $\left(\mathrm{A}^{1}\right)$, to the "low prob of zero" pie $\left(\mathrm{A}^{2}\right)$. In our examples this effect dominates all else. 


\section{References}

Bolton, G.E. (1991). "A Comparative Model of Bargaining: Theory and Evidence", American Economic Review 81(5), 1096-1136.

Croson, R.T.A. (1996). "Information in Ultimatum Games: An Experimental Study", Journal of Economic Behavior and Organisation 30(2), 197-213.

Eckel, C.C., and Grossman, P. (1996). "Altruism in Anonymous Dictator Games", Games and Economic Behaviour 16(2), 181-191.

Guth, W., Schmittberger R., and Schwarze, B. (1982). "An Experimental Analysis of Ultimatum Bargaining", Journal of Economic Behaviour and Organisation 3, 367-388.

Hoffman, E., McCabe K., Shachat, and Smith, V. (1994). "Preferences, Property Rights and Anonymity in Bargaining Games", Games and Economic Behavior, 7(3), 346-80.

Hoffman, E., McCabe K., and Smith, V. (1996). "Social Distance and Other-Regarding Behavior in Dictator Games", The American Economic Review 86(3), 653-660.

Ochs, J., and Roth, A.E. (1989). "An Experimental Study of Sequential Bargaining", American Economic Review 79, 355-84.

Ortona, G. (1991). "The Ultimatum Game. Some New Experimental Evidence", Economic Notes by Monte dei Pasci di Siena 20(2), 324-334. 
Rabin, M. (1993). "Incorporating Fairness into Game Theory and Economics”, The American Economic Review 83(5), 1281-1302.

Rubenstein, A. (1982). "Perfect Equilibrium in a Bargaining Model", Econometrica, 50, 97-109.

Stahl, I. (1972). Bargaining Theory, Economic Research Institute, Stockholm.

Straub, P.G., and Murnighan, K.J. (1995). An Experimental Investigation of Ultimatum Games: Information, Fairness, Expectations, and Lowest Acceptable Offers, Journal of Economic Behavior and Organisation, 27(3), 345-364.

Thaler, R.H. (1988). "Anomolies: The Ultimatum Game", The Journal of Economic Perspectives, 2(4), 195-206. 
Figure 1

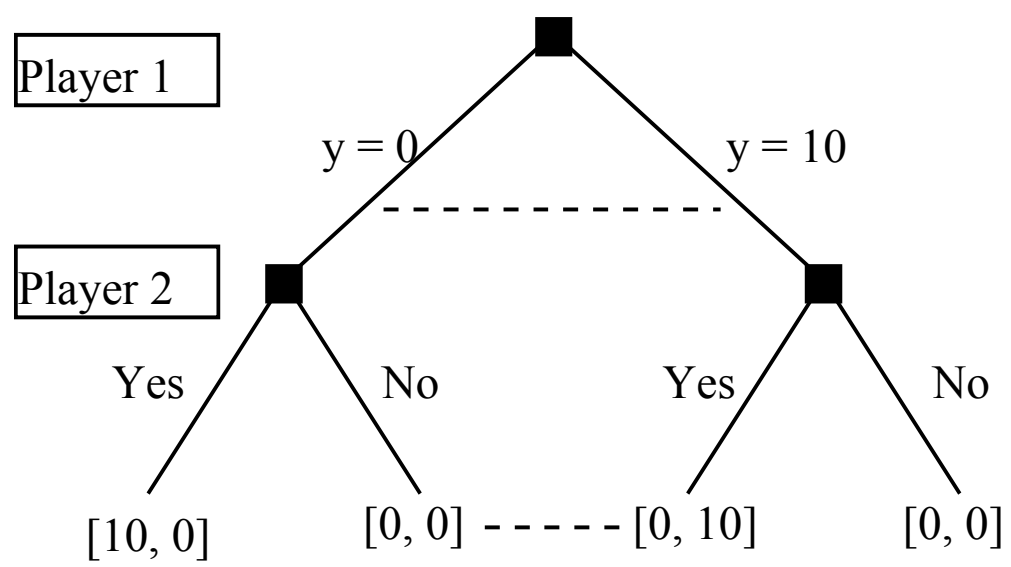

Figure 1 
Figure 2

\section{Expected Utility Under Risk Neutrality}

$$
(a=0.8227, c=0.6776, d=0.5)
$$

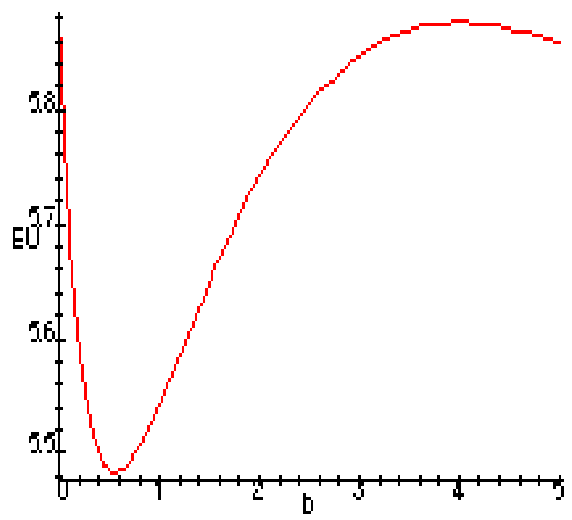

Figure 2 
Figure 3

Expected Utility and the Optimal Offer

$\operatorname{EU}(a=0.0, c \in(0.3,0.7), y \in(0.0,4.8), d=1.0)$

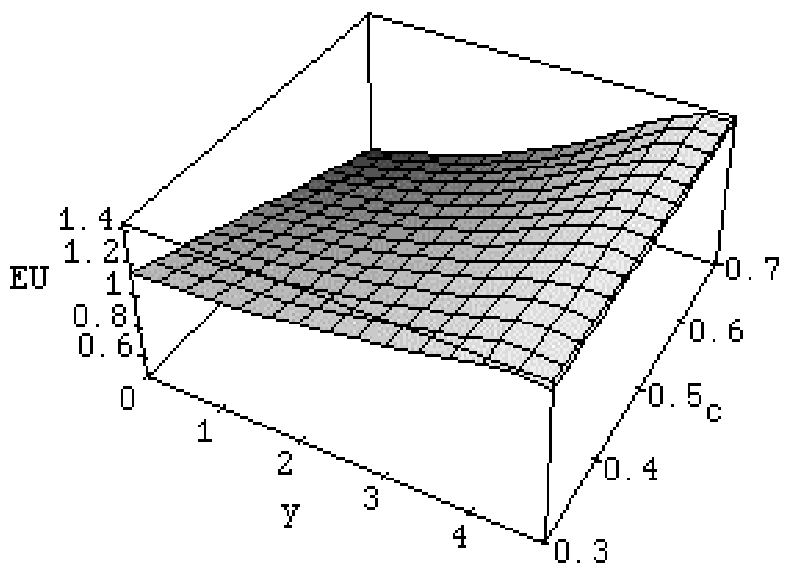

Figure 3: $q=0.2$ 
Figure 4

Figure 4: $q=0.5$ 
Figure 5

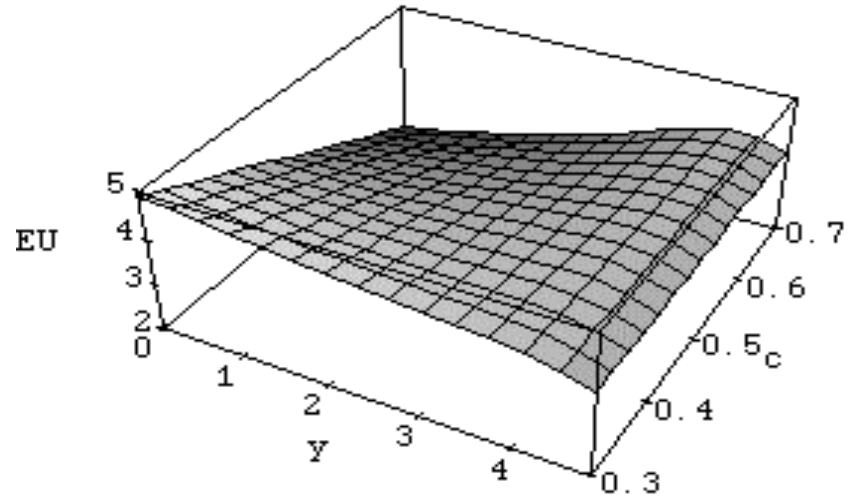

Figure 5: $q=0.8$ 
Figure 6

The Optimal Offer and Player 1's Expected Utility

Under Increasing Strength of Network Relationships

$(\mathrm{a}=0.0, \mathrm{c}=0.7, \mathrm{~d}=0.5, \mathrm{y} \in(0.0,4.9), \mathrm{z}=(6,8,10))$

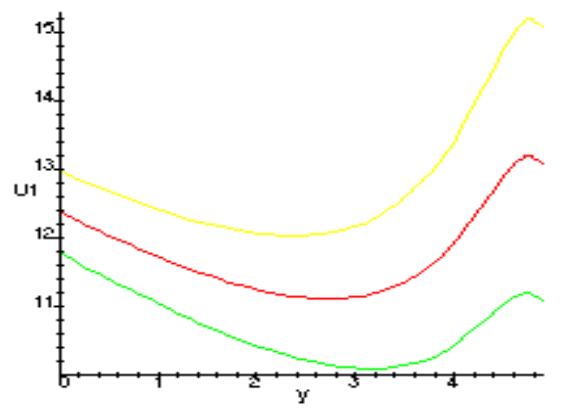

Figure $6^{11}$ 
Footnotes

${ }^{1}$ If Player 1 assigns a probability, $\mathrm{p}>0$, for Player 2 rejecting an offer of $\mathrm{y}=0$, a (unique) subgame perfect equilibrium exists only if it is assumed that money has a smallest unit, $\varepsilon$; yielding an equilibrium $\{y=\varepsilon$, yes $\}$.

2 An implication of Assumption 4(iv) is that $\partial \mathrm{U} / \partial \mathrm{W}) .(\mathrm{W} / \mathrm{U})<$ $[\partial(\partial \mathrm{U} / \partial \mathrm{q}) / \partial \mathrm{W}] .(\mathrm{W} /(\partial \mathrm{U} / \partial \mathrm{q}))$ which is a restriction that bounds the elasticity of utility with respect to wealth by the elasticity of the marginal utility of the degree of risk aversion with respect to wealth. Clearly 4(iv) requires $\mathrm{U}_{\mathrm{wq}}>0$.

${ }^{3}$ Formally, we have not shown that the offer is monotonically increasing in $\mathrm{c}$ for all values of $\{c, d\}$ given a.

${ }^{4}$ The information structure does differ in that Croson op cit does no have a common knowledge prior for the distribution of the size of the pie.

${ }^{5}$ In fact, the approach of Straub and Murnighan (1995) does not fit precisely the case 5 specification in that the distribution of the total pie was not common knowledge to the participants.

${ }^{6}$ It might be considered that a mean preserving spread in the preference parameter indicates an increase in heterogeneity among responders. But because a mean preserving spread necessarily means an increased proportion of reponders with a zero preference parameter, this interpretation is not applicable.

7 Throughout this discussion we presume that players of the dictator game in experiments were not confused about the nature of the game. We recognize that 
experimenters went to some trouble to rule this out, and indeed the changed outcomes under complete anonymity is suggestive that they were successful.

${ }^{8}$ In an experiment where social distance is large - i.e. the questionnaire is such that the decisionmaker is encouraged to feel quite "unrelated" to the other player - a bi-modal distribution is again obtained.

${ }^{9}$ Eckel and Grossman (1996) report experimental findings in which respondent's that were represented as charities received larger offers. In addition to explanations that rest on perceptions of a "deserving" respondent, these results may be explained by reputation implications and possibilities of future contact or requirements. The latter explanations entail expectations.

${ }^{10}$ Formally, the players need not be specifically identified with each other: all that is required is knowledge that one was the proposer and the other the responder in the same experimental dictator game in the past.

${ }^{11}$ The intersections of the graphs with the vertical axis are increasing in $\mathrm{z}$. 